\title{
The Role of Caspase-3 Activation in Phencyclidine-Induced Neuronal Death in Postnatal Rats
}

\author{
Cheng Z Wang' and Kenneth M Johnson*,1,2 \\ 'Department of Pharmacology and Toxicology, University of Texas Medical Branch, Galveston, TX, USA; '2Department of Psychiatry and \\ Behavioral Sciences, University of Texas Medical Branch, Galveston, TX, USA
}

\begin{abstract}
This study determined the role of caspase-3 in phencyclidine (PCP)-induced neurodegeneration in postnatal rats. PCP administration to postnatal day 7 rats induced a dose-dependent increase in caspase- 3 enzymatic activity in frontal cortex, striatum, and hippocampus. Enzymatic activation was present at $4 \mathrm{~h}$, peaked between 6 and $12 \mathrm{~h}$, and disappeared by $24 \mathrm{~h}$. Further, cleaved caspase-3immunoreactive neurons were detected as early as $2 \mathrm{~h}$ in the cortex, and were found throughout the brain, including, in addition, the thalamus and striatum. Within the cingulate, frontal, parietal, and retrosplenial cortices, immunoreactivity was specific for layers II-IV (especially layer II). Neurons positive for both silver staining and terminal deoxynucleotidyl transferase biotin-d-UTP nick-end labeling (TUNEL) were found in the same brain regions and subregions. Double labeling experiments confirmed that cleaved caspase-3 and TUNEL were coexpressed in many neurons in all brain regions and subregions studied. Temporal studies revealed that procaspase- 3 cleavage preceded TUNEL staining by about $3 \mathrm{~h}$, with many neurons being positive for both caspase-3 and TUNEL $9 \mathrm{~h}$ after PCP treatment. In organotypic corticostriatal slices, PCP caused a concentration- and time-dependent cleavage of procaspase-3 that was also colocalized with TUNEL staining in layers II-IV of the parietal cortex. Caspase-3 activation again preceded PCP-induced DNA damage assessed by TUNEL. PCP-induced neuronal death in vitro as measured by TUNEL staining was blocked $85 \%$ by AcAAVALLPAVLLALLAPDEVD-CHO, a cell-permeable selective caspase-3 inhibitor. These data demonstrate that caspase-3 activation plays a necessary role in the regionally selective neuronal death induced by PCP in the developing rat brain.

Neuropsychopharmacology (2007) 32, I I78-I 194. doi:I0. I038/sj.npp. I 30 I202; published online 20 September 2006
\end{abstract}

Keywords: caspase-3; phencyclidine; development; schizophrenia; neurodegeneration; apoptosis

\section{INTRODUCTION}

Acute phencyclidine (PCP) intoxication has long been recognized to mimic certain features of schizophrenia, including both negative and positive symptoms (Luby et al, 1959; Javitt and Zukin, 1991). The recognition that most of the acute effects of PCP are mediated by use-dependent blockade of the $N$-methyl-D-aspartate (NMDA) receptor (Lodge and Johnson, 1990) coupled with the observation that high-dose PCP caused neuronal vacuolization (Olney et al, 1989; Fix et al, 1993) and heat shock protein 70 activation (Sharp et al, 1994) gave rise to a hypoglutamatergic hypothesis of schizophrenia (Olney and Farber, 1995; Olney et al, 1999). More recently, observations of postmortem brains of schizophrenics have found structural and functional abnormalities that are likely to have arisen

*Correspondence: Dr KM Johnson, Department of Pharmacology and Toxicology, University of Texas Medical Branch, Galveston, TX 77555I03I, USA, Tel: + I 409772 9623, Fax: + I 409772 9642,

E-mail: kmjohnso@utmb.edu

Received I4 February 2006; revised 10 July 2006; accepted 26 July 2006

Online publication: 3 August 2006 at http://www.acnp.org/citations/ Npp080306060095/default.pdf during development (Benes and Berretta, 2001; Clinton and Meador-Woodruff, 2004; Jarskog et al, 2005; Kasai et al, 2002; Lewis, 2000; Lipska, 2004). These data have caused a shift towards developmental models of schizophrenia (Weinberger, 1997; Benes and Berretta, 2001; Harrison and Weinberger, 2005). Coincidentally, it has been reported that administration of NMDA receptor (NMDAR) antagonists to postnatal rodents induced neuronal death in specific brain regions, including the cerebral cortices, hippocampus, thalamus, and striatum (Gould et al, 1994; Ikonomidou et al, 1999; Fiske and Brunjes, 2001; Sattler and Tymianski, 2001; Wang et al, 2001; Wang and Johnson, 2005). These neurotoxic effects are known to be developmentally regulated (Ikonomidou et al, 1999; Wang and Johnson, 2005). This observation has raised questions about the mechanisms underlying neurodegeneration caused by NMDAR blockade, including its regional and developmental dependence. Defining these mechanisms may allow the exploration of potential relationships between neuronal apoptosis during brain development and diseases such as schizophrenia and bipolar disorder which appear to have a developmental etiology (Rapoport et al, 2005). This knowledge could lead to more rational drug development (Krystal et al, 2003). 
Caspase-3, the most prevalent caspase in the cell and an important member of a family of cysteine proteases (Yuan et al, 1993), has been widely reported to be the key executioner caspase in apoptosis (Cohen, 1997). Active caspase-3 cleaves many substrates such as poly(ADPribose) polymerase-1 (PARP) and ICAD (inhibitor of caspase-activated DNase) that result in key morphological alterations involved in apoptosis (Fischer et al, 2003). Caspase- 3 activation in postnatal rodent brain has been reported after administration of NMDA antagonists (Adams et al, 2004; Monti and Contestabile, 2000; Yoon et al, 2003; Scallet et al, 2004; Young et al, 2005). However, the precise relationship between caspase-3 activation and postnatal neuronal death following NMDAR blockade is incompletely understood.

Therefore, this study explored the relationship between PCP-induced caspase- 3 activation and neuronal death in vivo by monitoring caspase- 3 enzymatic activity, cleaved caspase-3 immunocytochemical expression, and terminal deoxynucleotidyl transferase biotin-d-UTP nick-end labeling (TUNEL) as a marker of apoptosis. This relationship was further characterized by including PCP dose and time as independent variables. Finally, similar experiments were carried out using in vitro application of PCP to organotypic corticostriatal slices. This allowed the use of selective, peptide-based, caspase-3 inhibitors to definitively determine the role of caspase- 3 cleavage in PCP-induced cell death.

\section{MATERIALS AND METHODS}

\section{Reagents}

PCP was acquired from the National Institute on Drug Abuse (Rockville, MD, USA) and dissolved in $0.9 \%$ $\mathrm{NaCl}$. Slice culture media including Hank's balanced salt solution (HBSS), heat-inactivated horse serum, OPTIMEM medium, neurobasal medium, and B-27 supplement were purchased from Invitrogen Corporation (Carlsbad, CA, USA). The caspase-3 substrate acetyl-Asp-Glu-Val-Asp7-amino-4-trifluorocumarin (Ac-DEVD-AFC) and the caspase-3 inhibitor Z-DEVD-FMK were purchased from MP Biomedicals (Livermore, CA, USA). Ac-AAVALLPAVLLALLAPDEVD-CHO (Ac-A PDEVD-CHO) was purchased from Axxora Life Science (San Diego, CA, USA). Primary antibodies against cleaved caspase-3 (Asp175) were obtained from Cell Signaling Technology (Danvers, MA, USA), and those against NeuN (neuronspecific protein) and GFAP (glial fibrillary acidic protein) were purchased from Chemicon International (Temecula, CA, USA). Deoxynucleotidyl transferase (TdT) and biotin-16-dUTP were purchased from Roche Diagnostics (Indianapolis, IN, USA). Secondary biotinylated goat antibodies against rabbit IgG or mouse IgG, ABC Elite Kit, and substrates were from Vector Laboratories (Burlingame, CA, USA). Fluorescence-conjugated streptavidin and secondary goat antibodies against rabbit IgG or mouse IgG were purchased from Invitrogen Corporation (Carlsbad, CA, USA). All other reagents were purchased from Sigma Chemicals (St Louis, MO, USA).

\section{Animals}

Timed pregnant Sprague-Dawley rats were obtained from Charles River Laboratories, Inc. (Wilmington, MA). They were housed individually with a 12-h light-dark cycle (lights on at 0700 hours, off at 1900 hours) in a temperature- and humidity-controlled environment with free access to food and water. After parturition, litters were culled to 8-12 pups with equal numbers of each gender and were kept in the same cage with their mothers until the end of experiment. On postnatal day 7 (P7), the pups were randomly assigned to either control or treatment groups, keeping the number of each gender in each treatment group as equal as possible; the number of each gender in each treatment group was adjusted across litters to insure equal numbers of each in each treatment group. For in vitro slice culture experiments, P2 pups from two litters were mixed with equal numbers of each gender from each litter. Slices were made from randomly selected pups, except that female and male pups were chosen alternately.

\section{Experimental Paradigms}

For in vivo experiments, P7 rat pups were injected subcutaneously with a single dose of either PCP $(1,3$, or $10 \mathrm{mg} / \mathrm{kg})$ or saline $(10 \mathrm{ml} / \mathrm{kg})$. Pups were then killed by decapitation at various survival times after saline or PCP injection to collect samples for caspase-3 enzymatic activity measurements and morphological and morphometric evaluation (see below for specific procedures). For in vitro experiments, cultured organotypic slices were exposed to saline or PCP $(0.3,1,3$, or $10 \mu \mathrm{M})$, and then collected at different intervals after drug treatment for measurement of caspase-3 enzymatic activity as well as morphological and morphometric analysis. The studies reported in this publication, bearing the imprimatur of the American College of Neuropsychopharmacology, have been carried out in accordance with the Declaration of Helsinki and/or with the Guide for the Care and Use of Laboratory Animals as adopted and promulgated by the National Institutes of Health.

\section{Organotypic Corticostriatal Slice Culture}

This was carried out as previously described (Stoppini et al, 1991; Noraberg et al, 1999). Briefly, brains from P2 rats were immersed in dissection medium (HBSS, with $25 \mathrm{mM} \mathrm{D-}$ glucose, $30 \mathrm{mM} \mathrm{KCl}$, and $1 \%$ penicillin-streptomycin), and cut coronally to $400 \mu \mathrm{m}$ slices by a McIlwain tissue chopper. The slices were transferred to OPTI-MEM medium (50\% OPTI-MEM, 25\% heat-inactivated horse serum, and $25 \%$ HBSS supplemented with $25 \mathrm{mM}$ D-glucose and $1 \%$ penicillin-streptomycin). Only slices with morphology comparable to levels between A5.3 and $\mathrm{A} 6.8 \mathrm{~mm}$ in P10 rats (Sherwood and Timiras, 1970) were selected and cultured in inserts (Millicell, Millipore, Bedford, MA, USA) in six-well plate. Two intact slices, in which the striatum, cortex, septum, and lateral ventricles were clearly visible, were transferred onto a Millicell-CM $0.4 \mu \mathrm{m}$ porous membrane on each insert. After the slices were carefully positioned in the center of the membrane, the medium in the insert was removed and replaced with $1.1 \mathrm{ml}$ of fresh OPTI-MEM 
medium in each well. The slices were then cultured for $10-11$ days at $37^{\circ} \mathrm{C}$ and $5 \% \mathrm{CO}_{2}$. After 4 days in vitro (DIV4, DIV0 $=\mathrm{P} 2)$, medium was replaced with Neurobasal medium supplemented with D-glucose $(25 \mathrm{mM})$, L-glutamine $(1 \mathrm{mM})$, B-27 (2\%), and penicillin-streptomycin (1\%). Thereafter, medium was changed twice per week.

It should be noted that we observed some gradual spontaneous neuronal death for unknown reasons in these slices soon after incubation. In some regions, particularly the striatum, but also including to a lesser extent the septum and the deep layers (V-VI) of the cortex, spontaneous neuronal death continued and left few viable neurons after DIV7. Thus, these regions were not suitable for experimentation. However, in the subregion of cortical layers I-IV, the spontaneous cell death subsided within a few days after culture and stopped at about DIV7. In fact, cortical layers I-IV, especially that of the parietal cortex, survived for at least 3 weeks and were suitable for cellular and molecular studies at least this long. The frontal and cingulate cortical subregions were often touched during positioning and flattening of the slice in the center of membrane and showed a small amount of cell death even after DIV7. Therefore, we selected layers II-IV of the parietal cortical to model and monitor cell death by TUNEL and cleaved caspase- 3 immunoreactivity. Preliminary studies noted that PCP treatment caused cell death in the superficial cortical layers (II-IV) only in a specific time window, with caspase-3 activation and neuronal death peaking after PCP exposure on DIV10-12 and then disappearing at DIV15. This was very similar to that found in vivo in that cortical layers II-IV were most sensitive to PCP between P4 and P11 and then became unresponsive by P21 (unpublished observations and Ikonomidou et al, 1999).

\section{Measurement of Caspase-3 Enzyme Activity}

Caspase-3 enzyme activity was monitored using a fluorometric assay as described (Stefanis et al, 1996; Kudryashov et $a l, 2001)$. The fluorogenic tetrapeptid substrate AcDEVD-AFC, which mimics the known cleavage site of PARP (DEVD:G) and has the highest affinity for the substrate (Stefanis et al, 1996), was used to determine the activity of caspase-3 (CPP32, YAMA). The AFC conjugate normally emits blue light $\left(l_{\max }=400 \mathrm{~nm}\right)$, but upon proteolytic cleavage the free AFC emits a yellow-green fluorescence at $505 \mathrm{~nm}$. Preliminary experiments demonstrated a linear increase in caspase- 3 activity over a substrate concentration range of $3-100 \mu \mathrm{M}$ (data not shown). Therefore, all subsequent assays were run at a concentration of $25 \mu \mathrm{M}$, which is very near the $K_{\mathrm{m}}$ value as determined below.

The frontal cortex (the entire cortex anterior to the genu of the corpus callosum), striatum, hippocampus, and medulla, or in vitro slices were placed in ice-cold lysis buffer containing $25 \mathrm{mM}$ HEPES ( $\mathrm{pH} 7.4$ ), $5 \mathrm{mM} \mathrm{MgCl}_{2}$, $1.5 \mathrm{mM}$ EDTA, 1.0 mM EGTA, $1 \mathrm{mM}$ dithiothreitol, $0.1 \%$ Triton X-100, and $1 \%$ protease inhibitor cocktail (Sigma). The tissue was then homogenized by hand using a Teflon pestle and glass homogenizer and left for $15 \mathrm{~min}$ on ice before centrifugation at $13100 \mathrm{~g}$ for $5 \mathrm{~min}$ at $4{ }^{\circ} \mathrm{C}$. The supernatants were kept on ice for immediate assay or stored at $-80^{\circ} \mathrm{C}$ for later measurement. Each sample was prepared in two parallel sets. One set consisted of an equal volume of supernatant and assay buffer (100 mM HEPES ( $\mathrm{pH} 7.4)$, $2 \mathrm{mM}$ dithiothreitol, $0.1 \%$ CHAPS, and $1 \%$ sucrose) in two samples. The other set was identical except that it also contained the selective caspase-3 inhibitor, Z-DEVD-FMK $(0.5 \mu \mathrm{M})$. After $15 \mathrm{~min}$ incubation at room temperature, the caspase- 3 substrate, Ac-DEVD-AFC $(25 \mu \mathrm{M})$, was added and the samples were then incubated at $37^{\circ} \mathrm{C}$ for $60 \mathrm{~min}$. Fluorescence resulting from cleavage of the substrate was monitored using the microplate fluorometer (Fluoroskan Ascent, Labsystems, Helsinki, Finland) at excitation and emission wavelengths of 405 and $510 \mathrm{~nm}$, respectively. 7Amino-4-trifluoromethyl-cumarin (AFC) was used as a fluorescent standard. Caspase-3 activity was calculated as the difference between substrate degradation rate in samples containing and not containing Z-DEVD-FMK. Caspase- 3 activity was measured over $60 \mathrm{~min}$ and expressed as pmoles $\mathrm{AFC} / \mathrm{mg}$ protein $/ 60 \mathrm{~min}$. Protein was measured by the bicinchoninic acid (BCA) technique (Smith et al, 1985). The concentration of Z-DEVD-FMK chosen to define caspase- 3 activity was based on five independent determinations of inhibition of total Ac-DEVDase activity in striatal homogenate $6 \mathrm{~h}$ following activation of the enzyme by the two doses of ethanol $(2.5 \mathrm{~g} / \mathrm{kg}$; i.p.) given $2 \mathrm{~h}$ apart (Olney et al, 2002). In these experiments, Z-DEVD-FMK produced essentially complete inhibition of Ac-DEVDase activity at $0.5 \mu \mathrm{M}$. The $\mathrm{IC}_{50}$ value calculated by fitting the data to a four-parameter sigmoidal curve was $11 \pm 2 \mathrm{nM}$, with a Hill slope of $0.98 \pm 0.07$, thereby suggesting that inhibition of Ac-DEVDase activity by Z-DEVD-FMK over this concentration range was either due to inhibition of a single enzymatic activity or of multiple enzymatic activities with identical affinities for the inhibitor.

\section{Processing Brain Sections or Slices for Morphological Studies}

As described previously (Wang and Johnson, 2005), after deep anesthesia with $100 \mathrm{mg} / \mathrm{kg}$ pentobarbital sodium, postnatal rats were perfused through the left ventricle and ascending aorta with ice-cold heparinized $(10 \mathrm{U} / \mathrm{ml})$, phosphate-buffered saline (PBS, $0.01 \mathrm{M}$ for immunohistochemistry, IHC), or Tris-buffered saline (TBS, $0.1 \mathrm{mM}$ for cupric silver stain) followed by ice-cold $4 \%$ paraformaldehyde in PBS (for IHC) or in TBS (for silver stain). The perfused brain was postfixed by immersion in the same fixative for $24 \mathrm{~h}$ for IHC and TUNEL or at least 2 days for cupric silver staining before sectioning. By using a P10 atlas (Sherwood and Timiras, 1970) as a guide, one hemisphere from each brain was serially cut on a Vibratome into $70 \mu \mathrm{m}$ thick sagittal sections (approximately 2-3.2 $\mathrm{mm}$ lateral to midline), and the other hemisphere was serially cut into $70 \mu \mathrm{m}$-thick coronal sections (approximately A5.3A6.8 $\mathrm{mm}$ ). The coronal sections were used to define the anterior extent of the striatum and the frontal, cingulated, and anterior parietal cortices, while medial striatum, thalamus (nucleus anterior ventralis), hippocampus, and subiculum/retrosplenial cortex were identified in the sagittal sections. By following the principles of unbiased, systematic random sampling (West, 1993), 18 serial sections were transferred into one of six wells, with every sixth section being placed in the same well with antifreeze 
solution and kept at $-20^{\circ} \mathrm{C}$ (for IHC and TUNEL) or with $4 \%$ paraformaldehyde (for cupric silver staining). In vitro organotypic slices were washed twice with HBSS, fixed with $2 \%$ paraformaldehyde for $1 \mathrm{~h}$ at room temperature or overnight at $4{ }^{\circ} \mathrm{C}$, washed twice with $\mathrm{PBS}$ and kept in antifreeze solution at $-20^{\circ} \mathrm{C}$.

\section{Histochemistry}

DeOlmos cupric silver staining was carried out according to a previous description (Carlsen and De Olmos, 1981) and used to detect the distribution and extent of neuronal degeneration. Nissl staining was performed to demonstrate normal brain morphology.

\section{IHC}

For IHC staining of cleaved caspase-3, free-floating sections or cultured slices were removed from antifreeze solution, placed in a 24-well plate, and washed with 0.01 M PBS. Cultured slices were then treated in $0.04 \%$ pepsin (in $10 \mathrm{mM}$ $\mathrm{HCl}$ ) for $15 \mathrm{~min}$ followed by PBS washes. Sections or slices were quenched for $10 \mathrm{~min}$ in $3 \%$ hydrogen peroxide/ methanol, washed with PBS, blocked for $1 \mathrm{~h}$ with blocking solution ( $2 \%$ normal goat serum $/ 2 \%$ BSA $/ 0.2 \%$ milk $/ 0.1 \%$ Triton X-100 in PBS) and incubated overnight with rabbit anticleaved caspase-3 (Asp175, 1:1000). After washes with PBS, the sections and slices were incubated for $1 \mathrm{~h}$ with secondary biotinylated goat anti-rabbit antibodies, washed with $\mathrm{PBS}$, and reacted in the dark for $1 \mathrm{~h}$ with $\mathrm{ABC}$ reagents (standard Vectastain ABC Elite Kit; Vector Laboratories, Burlingame, CA). After washes with PBS, the sections or slices were developed with a filtered mixture of Vector SG substrate (gray) or with $\mathrm{DAB}$ substrate (brown) (Vector Laboratories, Burlingame, CA).

\section{TUNEL}

To detect DNA fragmentation in neurons undergoing endstage apoptosis, coronal and sagittal brain sections from in vivo experiments and cultured organotypic slices were processed for TUNEL staining as described previously (Gavrieli et al, 1992) with modification. Free-floating sections and slices were placed in 24-well plates, incubated in pepsin $(0.04 \%$ in $10 \mathrm{mM} \mathrm{HCl})$, rinsed again with $0.01 \mathrm{M}$ PBS and quenched in $3.0 \%$ hydrogen peroxide in methanol for $10 \mathrm{~min}$. After rinsing with PBS, they were transferred to TdT reaction buffer $(30 \mathrm{mM}$ Tris- $\mathrm{HCl}, \mathrm{pH} 7.2,140 \mathrm{mM} \mathrm{Na}$ cacodylate, and $1 \mathrm{mM} \mathrm{CoCl}$ ) for $10 \mathrm{~min}$, and then incubated with biotin-16-dUTP $(10 \mathrm{nmol} / \mathrm{ml})$ (Roche) in the TdT buffer with (for positive controls and unknown samples) or without (for negative controls) TdT (200 U/ml) (Roche) in a humidified chamber for $2 \mathrm{~h}$ at $37^{\circ} \mathrm{C}$. Sections were then washed in $\mathrm{PBS}$, incubated with $\mathrm{ABC}$ reagents (standard Vectastain $\mathrm{ABC}$ Elite Kit; Vector Laboratories, Burlingame, CA) for $60 \mathrm{~min}$ (in DARK), and stained with a filtered mixture of Vector SG peroxidase substrate (Vector Laboratories, Burlingame, CA). TUNEL-methyl green counterstaining was carried out by first completing TUNEL staining with the brown DAB color, then mounting sections or slices on gelatinized slides, and finally staining with $0.5 \%$ methyl green.

\section{Multiple Labeling}

Double labeling of TUNEL and cleaved caspase-3 was carried out by in situ TUNEL staining with brown color development using $\mathrm{DAB}$ as a substrate followed by cleaved caspase-3 IHC with gray color employing Vector SG as the substrate. Immunofluorescent multiple labeling of cleaved caspase-3 (1:1000), NeuN (1:500), and GFAP (1:2000); or TUNEL, NeuN, and GFAP; or TUNEL, caspase-3, and NeuN was carried out in the following order: single labeling of NeuN or TUNEL followed by double-labeling of cleaved caspase- 3 and GFAP or NeuN and GFAP, or cleaved caspase-3 and NeuN. Specimens were visualized using a Zeiss LSM510 META confocal system configured with a Zeiss Axiovert $200 \mathrm{M}$ motorized inverted microscope. All images were acquired using a C-Apochromat $\times 40(1.2 \mathrm{NA})$ water immersion objective and the scanning zoom was adjusted for optimal space sampling (pixel size 110 by $110 \mathrm{~nm}$ ). Multilabeled fluorescent samples were imaged acquiring each fluorescent channel sequentially to avoid signal bleed-over. The Alexa 488 component was obtained using the $488 \mathrm{~nm}$ line of an argon ion laser for excitation and a band pass $505-530 \mathrm{~nm}$ emission filter. The Alexa 594 component was obtained using the $543 \mathrm{~nm}$ line of a green helium/neon laser for excitation and a band pass 585$620 \mathrm{~nm}$ emission filter. The Alexa 633 component was obtained using the $633 \mathrm{~nm}$ line of a red helium/neon laser for excitation and a long pass $650 \mathrm{~nm}$ emission filter. A $Z$-axis scan was performed and stacks of images were taken at $1 \mu \mathrm{m}$ intervals spanning $20-34 \mu \mathrm{m}$ depending on the sample. Images were visualized and processed by using the Zeiss Image Browser freeware program.

\section{Quantitative Analysis of Images}

As previously described (Wang and Johnson, 2005), cleaved caspase-3 immunoreactive (caspase-3-IR) or TUNEL-positive cells were quantified on photomicrographs of the following brain regions as guided by using atlases for P10 pups or adult rats: cortices of cingulate (Cg), frontal (M1) and parietal (S1), and $\mathrm{CPu}$, Figure 13 (Paxinos and Watson, 1998); CA1/subiculum (CA1/Sub) and retrosplenial cortex (RSC), Figures 81-82 (Paxinos and Watson, 1998); and thalamus (nucleus anterior thalami), pages 72-75 (Sherwood and Timiras, 1970). The photomicrographs of each region were taken through a $10 \times$ (in vivo sections) or $20 \times$ (in vitro slices) objective using a Hammatsu digital camera (C4742-95) based on the following demarcation definitions: cingulate cortex, edges started ventrally at the beginning of the cingulate and medially at the outer edge of layer I; for frontal and parietal cortices, the edge started at the outer edge of layer I dorsally and laterally, respectively; for RSC, the edges started ventrally at the outer edge of layer I and rostrally at the beginning of RSC; for $\mathrm{CPu}$ (striatum), the lateral edge was centered at the middle of its most lateral margin; for CA1/Sub, the edges started ventrally at the outer edge of DG and RSC and caudally at the beginning of CA1; and for the thalamus, the edges started dorsally at the margin of nucleus anterior thalami and rostrally at the surface of the third ventricle. Photomicrographs $(\times 20)$ of layers II-IV of the parietal cortex of cultured slices were taken above a horizontal line right-angled with the outer edge of layer I of the cingulate cortex. 
The quantification was carried out by automatically measuring the number of positive neurons in a defined area of interest (AOI) (Figures 2 and 3) within the photomicrographs of each brain region by using a computer-based image analysis program, SimplePCI (Compix Inc. Imaging Systems, Cranberry Township, PA). For the $\mathrm{CPu}, \mathrm{CA} 1 / \mathrm{Sub}$, and thalamus, the entire region was circumscribed by eye in the original photomicrographs and the AOI $(\sim 1020 \times 1270$ pixels $)$ was circumscribed as described above for each. The cortical AOI was outlined in rectangles by hand defined as follows: all started at the outer edge of layer II medially (cingulate cortex, $400 \times 1020$ pixels), or dorsally (frontal cortex, $400 \times 1270$ pixels), or laterally (parietal cortex, $400 \times 1020$ pixels) and ventrally (RSC, $600 \times 1270$ pixels). The program converted all AOI thus defined automatically from pixels to $\mu \mathrm{m}^{2}$ based on calibration files. The number of positive cells was estimated by using a double threshold technique based on average neuronal size and gray level, in which two operators agreed that a gray range setting, along with the size discriminator, accurately counted the number of positive neurons. The gray level ranges were set up as follows: $20-127$ for TUNELpositive neurons, and 20-100 for cleaved caspase-3-IR neurons. Neuronal area sizes were set up to range between $6 \mu \mathrm{m}^{2}(\sim 2.8 \mu \mathrm{m}$ diameter $)$ and $100 \mu \mathrm{m}^{2}(\sim 11 \mu \mathrm{m}$ diameter $)$ for TUNEL, and between $6 \mu \mathrm{m}^{2}(\sim 2.8 \mu \mathrm{m}$ diameter $)$ and $250 \mu \mathrm{m}^{2}(\sim 18 \mu \mathrm{m}$ diameter $)$ for cleaved caspase- 3 . The extent of positive staining was expressed as the number of positive neurons $/ \mathrm{mm}^{2}$. The average value from all three sections taken from each region was used to represent the regional value for each animal.

\section{Statistical Analysis}

All experimental data are presented as the mean \pm SE. Oneway ANOVA with Dunnett's post hoc test was used to determine differences among more than two groups assayed at different time points following saline or PCP treatment or differences at one time following different doses of PCP. Unpaired $t$-test (two-tailed) was used to determine differences between two groups. Differences were considered significant at $p<0.05$.

\section{RESULTS}

\section{Effect of PCP on Caspase-3 Enzyme Activation in Specific Regions of Developing Rat Brains}

By using a fluorogenic tetrapeptide substrate, Ac-DEVDAFC, which mimics the known active caspase-3 cleavage site of PARP (DEVD:G) to determine the conversion of procaspase- 3 to active caspase- 3 , we found that a single dose of PCP induced caspase-3 activation in all regions of the developing brain measured (Figure 1). Eadie-Hofstee analysis of striatal activity $6 \mathrm{~h}$ following treatment with PCP $(10 \mathrm{mg} / \mathrm{kg})$ over a substrate range of $3-100 \mu \mathrm{M}$ revealed that PCP caused an increase in the maximal velocity $\left(V_{\max }\right)$ of the reaction by about $9( \pm 2)$-fold, with no change in $K_{\mathrm{m}}$ $(26 \pm 5 \mu \mathrm{M}$ for saline control and $23 \pm 4 \mu \mathrm{M}$ for PCP treatment), suggesting that the increase in enzymatic activity was most likely due to an increase in procaspase- 3 cleavage.
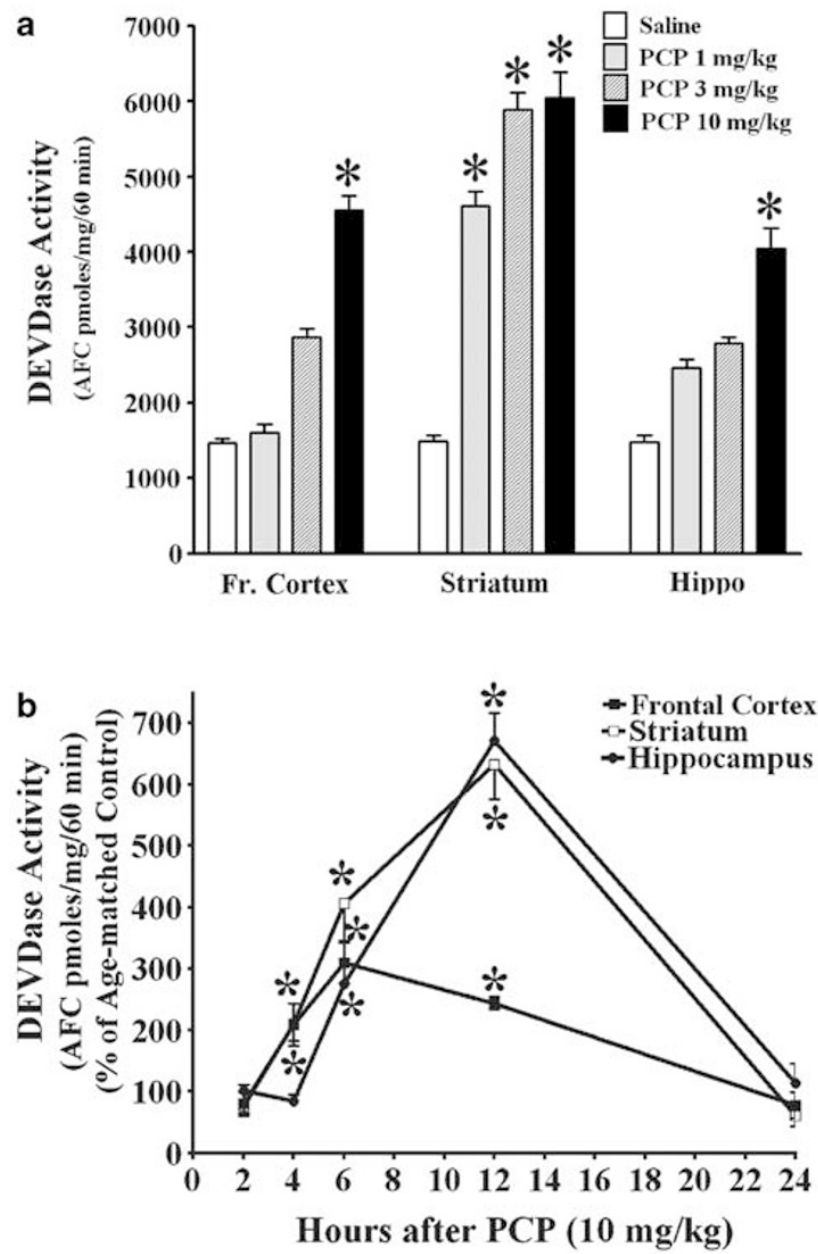

Figure I (a) PCP induces a dose-dependent increase in caspase-3 activity $6 \mathrm{~h}$ after a single dose (I, 3, or $10 \mathrm{mg} / \mathrm{kg}, \mathrm{s} . \mathrm{c}$.$) in frontal (Fr.) cortex$ $\left(F_{3,20}=20.5\right)$, striatum $\left(F_{3,20}=13.1\right)$, and hippocampus $\left(F_{3,14}=9.5\right)$; $N=4-6$ rats/group. ${ }^{*} p<0.05$ (one-way ANOVA, with Tukey's post hoc test). (b) Temporal and regional dependence of PCP $(10 \mathrm{mg} / \mathrm{kg})$-induced caspase- 3 activation; $N=4-6$ rats/group. ${ }^{*} p<0.05$ (unpaired $t$-test vs saline control at each time point).

PCP-induced caspase- 3 activation in developing brain was dose- and region-specific as illustrated in Figure 1a. Acute PCP induced a significant increase in caspase-3 activity in the frontal cortex, striatum, and hippocampus, but not in the medulla (data not shown). Caspase-3 activity increased in a dose-dependent manner $6 \mathrm{~h}$ after a single dose of PCP $(1,3$, or $10 \mathrm{mg} / \mathrm{kg}$, sc) in all three brain regions studied. The striatum was clearly the most sensitive, followed by the frontal cortex and finally by the hippocampus. Also, acute PCP $(10 \mathrm{mg} / \mathrm{kg})$ induced caspase-3 activity in a time- and regional-dependent manner (Figure 1b). In the frontal cortex, caspase-3 activity was not different from that of controls $2 \mathrm{~h}$ after PCP treatment, but was increased significantly by about two-fold at $4 \mathrm{~h}$ and about three-fold at $6 \mathrm{~h}$. Activity decayed at $12 \mathrm{~h}$ and was not significantly different from control after $24 \mathrm{~h}$. Caspase-3 activity in the striatum and hippocampus, however, showed a somewhat different time course, peaking at $12 \mathrm{~h}$ rather than $6 \mathrm{~h}$, before decaying to control values by $24 \mathrm{~h}$ posttreatment. 


\section{Effect of PCP on Cleaved Caspase-3 Expression and Apoptosis in Specific Regions and Subregions of Developing Rat Brains}

To determine the subregional distribution of activated caspase-3, an antibody specific for cleaved caspase- 3 was used; this antibody detects the large $(17 \mathrm{kDa})$ fragment, but does not recognize either the full-length procaspase- 3 or other cleaved caspases (Hu et al, 2000). As shown in Figures 2 and 3, cleaved caspase-3 immunoreactivity (caspase-3-IR) was expressed in cell soma as well as in dendritic processes (Figure 2b). Caspase-3-IR neurons were found in all brain regions studied. In the cingulate and retrosplenial cortices, most cleaved caspase-3-IR cells were found in layers II and IV (Figure $2 \mathrm{~b}$ and $\mathrm{d}$ ). In the frontal and parietal cortices, the greatest density of cleaved caspase-3-IR cells was found in layer II, with some in layer IV and very few in V (Figure 3a). In the hippocampus, most cleaved caspase-3-IR neurons were found in the CA1 (Figure 2c). Cleaved caspase-3-IR cells were distributed throughout the striatum (Figure $3 \mathrm{~g}$ ), including nucleus accumbens and in the thalamus (most prominently in the nucleus anterior thalami) (Figure 2e).
Administration of a single dose of PCP caused apoptotic cell death as measured by TUNEL in specific brain regions, including the cingulate, frontal, parietal, and retrosplenial cortices, $\mathrm{CA} 1 /$ subculum, striatum $(\mathrm{CPu})$, and thalamus (Table 2 and Figure 3). In these cortices, TUNEL-positive cells were expressed in layers II and IV, especially layer II (Figure 3b). TUNEL-positive cells were distributed in the same brain regions and subregions as that of cleaved caspase-3-IR cells and that of cupric silver-positive cells as well. Two brain regions are shown in Figure 3 as examples: in parietal cortex, positive cells of cleaved caspase-3 (Figure 3a), TUNEL (Figure 3b), and silver staining (Figure 3c) were all located in layers II-IV, especially layer II; in the striatum, cleaved caspase-3-positive cells (Figure 3g), TUNEL (Figure 3h), and silver staining (Figure 3i) were also expressed in similar density and location.

Additionally, double (bright field) or immunofluorescence multiple labeling was performed to determine whether cleaved caspase-3 was coexpressed with TUNEL in the same cells. Coexpression of both markers was found in both preparations (bright-field double staining (data not
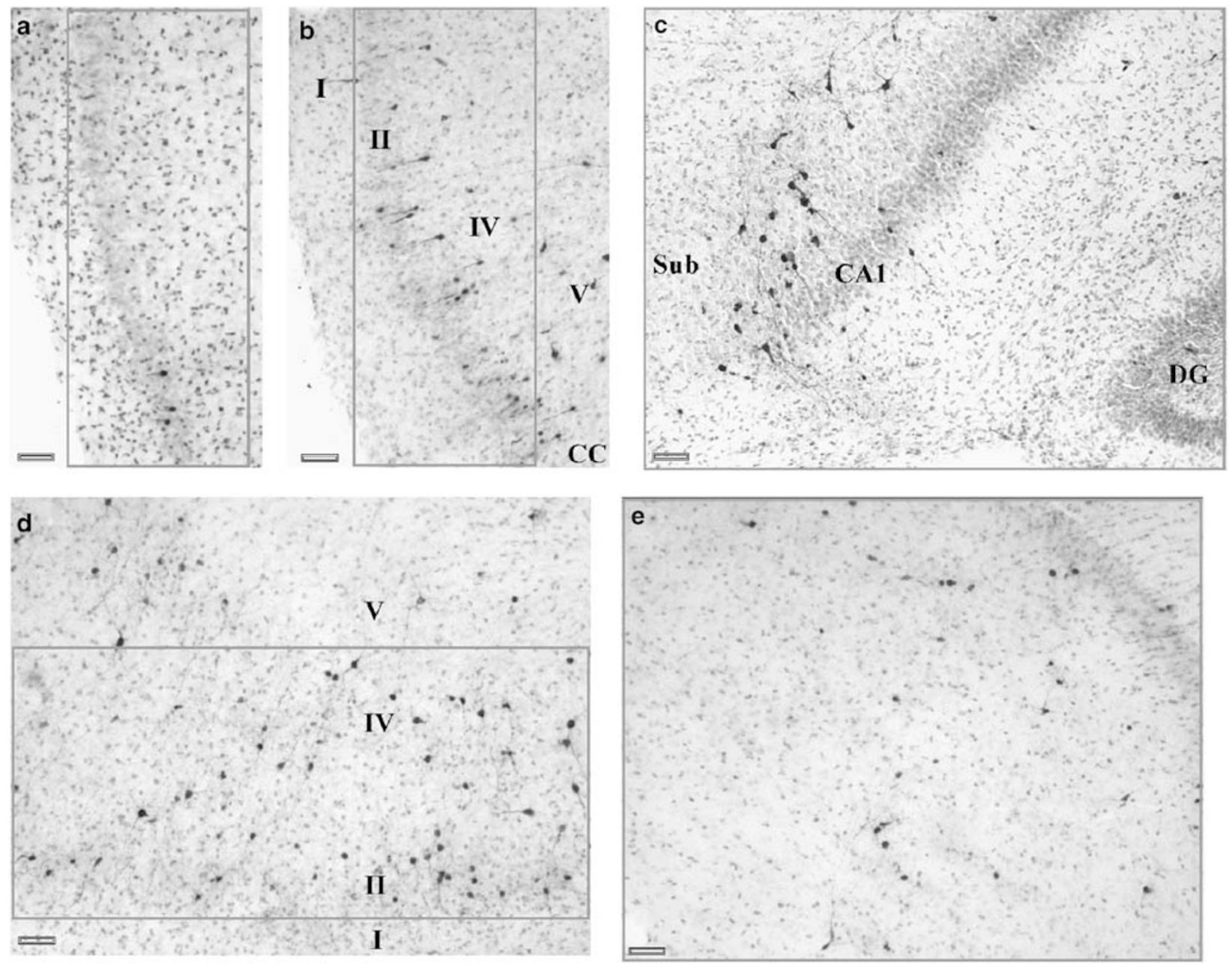

Figure 2 Region-specific caspase-3 activation $9 \mathrm{~h}$ after saline (a) or PCP (I0 mg/kg) exposure (b-e) in P7 rats. Very few cleaved caspase-3-IR neurons are found in saline-treated pup brains, for example, the ventral portion of the cingulate cortex (a), but many are in the cingulate cortex (b), hippocampus (CAI/ subiculum, $c$ ), retrosplenial cortex (d), and thalamus (nucleus anterior ventralis, e) after PCP administration. Rectangular boxes outlined in red are the areas of interest $(\mathrm{AOI})$ used for quantification of positive neurons in the specific brain region. Bars $=50 \mu$. 

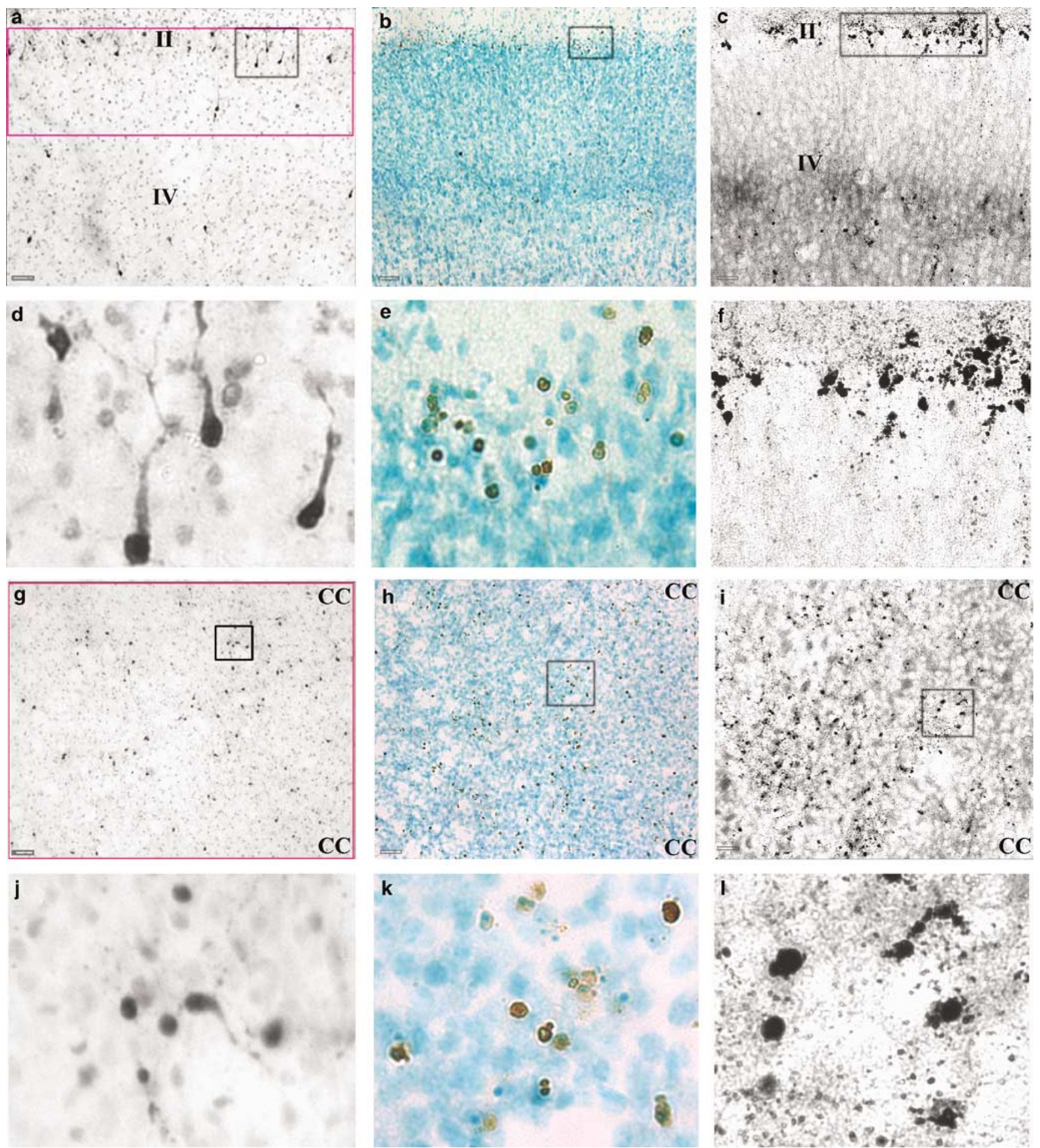

Figure 3 Subregional distribution of cleaved caspase-3-IR neurons (left-hand column), TUNEL-positive neurons, counterstained with methyl green (middle column) and cupric silver-positive neurons (right-hand column). At $9 \mathrm{~h}$ after $10 \mathrm{mg} / \mathrm{kg} \mathrm{PCP}$ on P7, all markers were found in parietal cortex (a-c) and striatum (g-i). Note that in the parietal cortex shown here as an example of the cerebral cortices (including cingulate and frontal), neurons positive for cleaved caspase-3 (a), TUNEL (b), and silver staining (c), were all located layers II-IV, especially layer II. Figures $\mathrm{d}-\mathrm{f}$ and $\mathrm{j}-\mathrm{I}$ are a higher magnification of the in-picture boxes in $\mathrm{a}-\mathrm{c}$ and $\mathrm{g}-\mathrm{i}$, respectively. Bars $=50 \mu$.

shown) and immunofluorescence multiple labeling) after PCP treatment. Figure 4 shows the CA1 region as an example. A $Z$-axis scan (Figure 4 f) clearly demonstrates double labeling in the same neuron in the late stage of apoptosis. Here, the fragmented nucleus is shown to be TUNEL positive (red) and the cytoplasm and a projection
(YZ-plane) are positive for cleaved caspase-3 (green). Depending on various stages of cell death, TUNEL-positive nuclei showed either single or multiple fragments, while cleaved caspase-3-IR in the cytoplasm and projection(s) varied in size from the whole soma to a small portion of the soma. As shown in Figure 4, most of the double-stained cells 

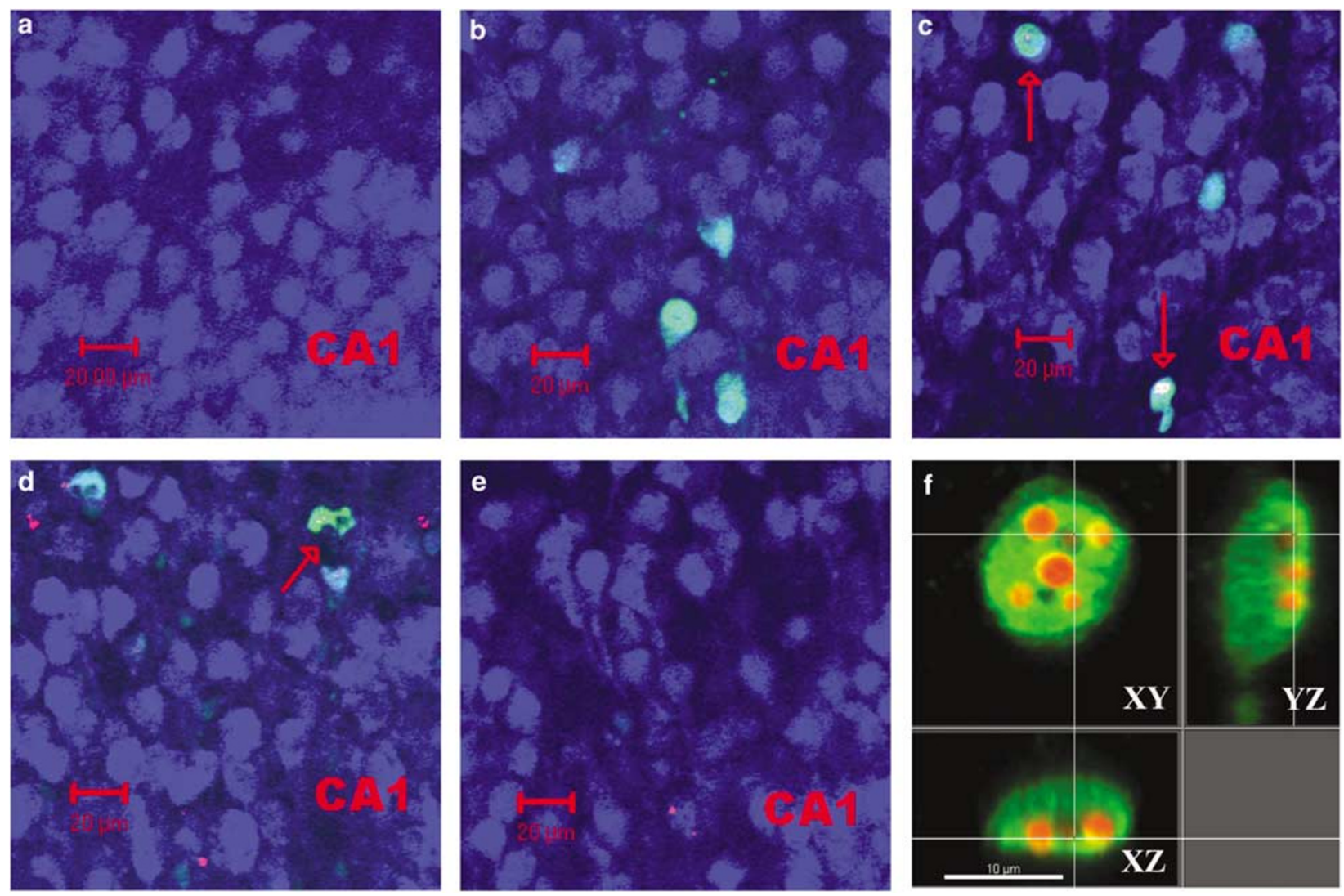

Figure 4 Time course for PCP ( $10 \mathrm{mg} / \mathrm{kg}$ )-induced cleavage of caspase-3 (green) and apoptosis (TUNEL, red) in hippocampal CAI neurons (labeled blue with NeuN, a neuron-specific protein). The effect of saline $(\mathrm{a}, 6 \mathrm{~h})$ is compared to $10 \mathrm{mg} / \mathrm{kg}$ PCP at different time intervals $(6 \mathrm{~h}, \mathrm{~b} ; 9 \mathrm{~h}, \mathrm{c} ; 16 \mathrm{~h}, \mathrm{~d} ; 24 \mathrm{~h}, \mathrm{e})$. Cleaved caspase-3-positive, TUNEL-negative, cells appear light blue-green and can be seen in (b), (c) and (d). Arrows in (c) (9 h) and (d) (16 h) point out double-labeled TUNEL- and caspase-3-positive cells in which the nucleus appears white. A few scattered TUNEL (only)-positive cells can be seen after I6 h (d) and $24 \mathrm{~h} \mathrm{(e).} \mathrm{(f)} \mathrm{Z-axis} \mathrm{scan} \mathrm{of} \mathrm{a} \mathrm{single} \mathrm{cell} \mathrm{(higher} \mathrm{magnification} \mathrm{of} \mathrm{the} \mathrm{arrow-labeled} \mathrm{neuron} \mathrm{near} \mathrm{the} \mathrm{bottom} \mathrm{of} \mathrm{(c))} \mathrm{showing} \mathrm{that} \mathrm{cleaved} \mathrm{caspase-3} \mathrm{is}$ largely confined to the cytoplasm surrounding a multifragmented nucleus $9 \mathrm{~h}$ after PCP administration. Bar $=20 \mu(\mathrm{a}-\mathrm{e})$ or $10 \mu(\mathrm{f})$.

were found $9 \mathrm{~h}$ after PCP treatment (Figure 4c), although some double-stained cells were present at $16 \mathrm{~h}$ (Figure $4 \mathrm{~d}$ ). TUNEL and cleaved caspase- 3 double labeling was found in many cells in all regions studied including all cortical regions, the thalamus, and striatum. Immunofluorescent multiple-labeling of the neuronal marker, NeuN (neuronspecific protein) and the glial marker, GFAP (glial fibrillary acidic protein, data not shown) showed that all doublestained cells were also NeuN positive (Figure 4).

\section{Time Course of Caspase- 3 Activation and Neuronal Death after Acute PCP Administration}

As shown in Figure 4, cleaved caspase-3-IR appeared in the CA1 region earlier than TUNEL. At $6 \mathrm{~h}$ following saline treatment, no caspase-3-positive neurons were found (Figure 4a), but after PCP, many neurons were positive for cleaved caspase-3-IR at this interval (Figure $4 \mathrm{~b}$ ). By $9 \mathrm{~h}$, significant double-staining was observed (Figure 4c), and by $16 \mathrm{~h}$, several were still TUNEL positive (Figure $4 \mathrm{~d}$ ). Very few neurons positive for either marker were found at $24 \mathrm{~h}$ (Figure 4e). This temporal profile was also found in other brain regions including striatum, thalamus, and cerebral cortices.

Computer-assisted quantitative analysis of caspase-3 immunoreactivity (Table 1) revealed similar, although distinct, dose and temporal patterns of response to PCP that varied in a regionally dependent fashion. In the retrosplenial, cingulate, and especially frontal and parietal cortices, the number of cleaved caspase-3-IR cells increased by 2 -3-fold at as early as $2 \mathrm{~h}$ after PCP administration, peaked at 5-11-fold at $9 \mathrm{~h}$, then decreased dramatically at $16 \mathrm{~h}$ and returned to control levels by $24 \mathrm{~h}$ (Table 1 ). The time course in the CA1/subiculum, dorsal striatum, and thalamus was somewhat delayed, but overall very similar to the cortical areas (Table 1).

Quantitative bright-field image analysis of TUNELpositive neurons showed time- and region-dependent neuronal death after administration of a single dose of PCP (Table 2). In all brain regions studied, the number of TUNEL-positive neurons showed no obvious change $2 \mathrm{~h}$ after PCP administration, but began to increase at $4 \mathrm{~h}$ and further increased significantly by about $3-6$-fold at $6 \mathrm{~h}$. This increase peaked at about eight-fold at $9 \mathrm{~h}$ (striatum) or 4-12-fold at $16 \mathrm{~h}$ in the cortices (cingulate, frontal, parietal, and retrosplenial), thalamus, and hippocampus. By $24 \mathrm{~h}$, all brain regions appeared similar to control.

It is important to point out that caspase-3 activation appeared to precede apoptotic neuronal death in all brain regions studied. This is most apparent in the frontal (Tables 1 and 2) and parietal cortices (see example, Figure 5a) in which significant caspase- 3 activation appeared as early as 
Table I Temporal Expression of Cleaved Caspase-3-Immunoreactive Neurons after Administration of Single Dose Phencyclidine (PCP) in P7 Rats

\begin{tabular}{|c|c|c|c|c|c|c|c|c|}
\hline \multirow{2}{*}{ Brain region } & \multirow{2}{*}{ Saline ${ }^{a}$} & \multicolumn{7}{|c|}{ Cleaved caspase- 3 immunoreactive cells $/ \mathrm{mm}^{2}$} \\
\hline & & \multicolumn{7}{|c|}{ PCP ( $10 \mathrm{mg} / \mathrm{kg}, \mathrm{sc})$} \\
\hline Cingulate Ctx & $11 \pm 1$ & $11 \pm 2$ & $22 \pm 5$ & $34 \pm 2 *$ & $50 \pm 5 *$ & $124 \pm 1 \mid *$ & $21 \pm 5$ & $14 \pm 1$ \\
\hline Frontal Ctx & $15 \pm 3$ & $14 \pm 1$ & $42 \pm 5^{*}$ & $45 \pm 2 *$ & $47 \pm 4 *$ & $91 \pm 11 *$ & $15 \pm 4$ & $14 \pm 2$ \\
\hline CAI/Subic & $8 \pm 1$ & $8 \pm 1$ & $15 \pm 3$ & $25 \pm 3$ & $33 \pm 2 *$ & $62 \pm 5^{*}$ & $30 \pm 13$ & $22 \pm 10$ \\
\hline $\mathrm{CPu}$ & $10 \pm 1$ & $9 \pm 1$ & $13 \pm 2$ & $25 \pm 1^{*}$ & $58 \pm 4 *$ & $157 \pm 32 *$ & $11 \pm 1$ & $\mid I \pm 1$ \\
\hline RSC & $13 \pm 1$ & $16 \pm 3$ & $20 \pm 3$ & $30 \pm 3 *$ & $47 \pm 2 *$ & $139 \pm 19 *$ & $34 \pm 11$ & $16 \pm 4$ \\
\hline Thalamus & $9 \pm 1$ & $9 \pm 1$ & $10 \pm 3$ & $20 \pm 1 *$ & $28 \pm 1 *$ & $66 \pm 3^{*}$ & $20 \pm 2$ & $12 \pm 1$ \\
\hline
\end{tabular}

${ }^{a}$ Saline was administered to control pups that were killed at either $3(N=1), 6(N=1), 9(N=2)$, and $24 \mathrm{~h}(N=1)$ post administration. These groups were combined for statistical analysis. $N=4-5$ for all treatment groups.

* $p<0.05$ vs corresponding saline value. One-way ANOVA, with Dunnett's post hoc test; cingulate cortex $\left(F_{7,27}=46.9\right)$, frontal cortex $\left(F_{7,27}=25.5\right)$, parietal cortex $\left(F_{7,27}=39.8\right)$, CAl/subiculum $\left(F_{7,26}=9.23\right)$, $C P u\left(F_{7,27}=16.8\right)$, retrosplenial cortex $\left(R S C, F_{7,26}=23.6\right)$, thalamus $\left(F_{7,26}=126\right)$.

Table 2 Temporal Profile of Neuronal Death (TUNEL) after Administration of Single Dose Phencyclidine in P7 Rats

TUNEL-positive cells $/ \mathrm{mm}^{2}$

\begin{tabular}{|c|c|c|c|c|c|}
\hline \multicolumn{6}{|c|}{ PCP $(10 \mathrm{mg} / \mathrm{kg}, \mathrm{sc})$} \\
\hline $2 \mathrm{~h}$ & $4 \mathrm{~h}$ & $6 \mathrm{~h}$ & $9 \mathrm{~h}$ & $16 \mathrm{~h}$ & $24 \mathrm{~h}$ \\
\hline $10 \pm 2$ & $11 \pm 2$ & $36 \pm 3 *$ & $86 \pm 8 *$ & $99 \pm 13^{*}$ & $12 \pm 3$ \\
\hline $21 \pm 6$ & $28 \pm 3$ & $43 \pm 3 *$ & $69 \pm 7 *$ & $72 \pm 6 *$ & $17 \pm 6$ \\
\hline $14 \pm 3$ & $27 \pm 2$ & $49 \pm 2 *$ & $68 \pm 4 *$ & $69 \pm 6 *$ & $28 \pm 7$ \\
\hline $\mid 1 \pm 1$ & $18 \pm 4$ & $71 \pm 15^{*}$ & $82 \pm 12 *$ & $80 \pm 10 *$ & $15 \pm 1$ \\
\hline $\mid 1 \pm 1$ & $10 \pm 2$ & $16 \pm 1$ & $59 \pm 8^{*}$ & $64 \pm 14 *$ & $23 \pm 3$ \\
\hline $15 \pm 3$ & $17 \pm 4$ & $55 \pm 2 *$ & $133 \pm 14 *$ & $181 \pm 17 *$ & $35 \pm 3$ \\
\hline $10 \pm 1$ & $12 \pm 2$ & $23 \pm 2 *$ & $55 \pm 8^{*}$ & $60 \pm 6 *$ & $27 \pm 4 *$ \\
\hline
\end{tabular}

${ }^{a}$ Saline was administered to control pups that were killed at $3(N=1), 6(N=1), 9(N=2)$, and $24 \mathrm{~h}(N=1)$ post administration. These groups were combined for statistical analysis. $N=4-5$ for all treatment groups.

${ }^{*} p<0.05$ vs corresponding saline value. One-way ANOVA, with Dunnett's post hoc test; cingulate cortex $\left(\mathrm{F}_{6,22}=91.3\right)$, frontal cortex $\left(\mathrm{F}_{6,22}=21.2\right)$, parietal cortex $\left(F_{6,22}=33.4\right), C P u\left(F_{6,22}=15.5\right)$, CAl/subiculum $\left(F_{6,21}=13.6\right)$, retrosplenial cortex $\left(\operatorname{RSC}, F_{6,21}=60.1\right)$, thalamus $\left(F_{6,21}=25.6\right)$.

$2 \mathrm{~h}$ (Table 1), about $4 \mathrm{~h}$ earlier than neuronal death which was significantly increased $6 \mathrm{~h}$ after PCP exposure (Table 2). Similarly, we observed that significant caspase- 3 activation appeared in the thalamus (Table 1) and striatum (Figure 5b) about $2 \mathrm{~h}$ before apparent neuronal death occurred $6 \mathrm{~h}$ after PCP exposure (Table 2).

\section{Effect of PCP on Caspase-3 Activation and Neuronal Death in Cerebral Cortices of Cultured Organotypic Slices}

Although these data suggest that procaspase-3 cleavage leads to apoptosis following PCP administration, to more firmly substantiate this we established an in vitro model of the cortex using organotypic cultures of corticostriatal slices. In this system, as illustrated in Figure 6, cultured slices at DIV10-11 (DIV0 = P2) showed time-dependent caspase-3 enzyme activation after PCP exposure, in which enzyme activity increased significantly at $6 \mathrm{~h}(p<0.01)$, peaked at $12 \mathrm{~h}$, and declined thereafter, although remaining significantly higher than controls $24 \mathrm{~h}$ after PCP treatment $(p<0.05)$ (Figure 6a). Caspase-3 enzyme activity measured $18 \mathrm{~h}$ after PCP exposure increased in a concentrationdependent manner, being activated 2.5 -fold by $0.1 \mu \mathrm{M}$ $(p<0.05), 3.3$-fold by $0.3 \mu \mathrm{M}, 3.7$-fold by $1 \mu \mathrm{M}$, and 4.8 fold by 3 and $10 \mu \mathrm{M}(p<0.001)$ (Figure $6 \mathrm{~b})$. These data suggest that this corticostriatal slice model mimics certain aspects of PCP-induced caspase- 3 enzyme activation in vivo.

Further experiments revealed that while untreated slices at DIV11 had only a few scattered cleaved caspase-3-IR neurons (Figure 7a), PCP $(3 \mu \mathrm{M})$-treated slices showed many in cortical layers II-IV (Figure $7 b$ and $c$ ). Under higher magnification (Figure 7c), these cleaved caspase-3-IR 

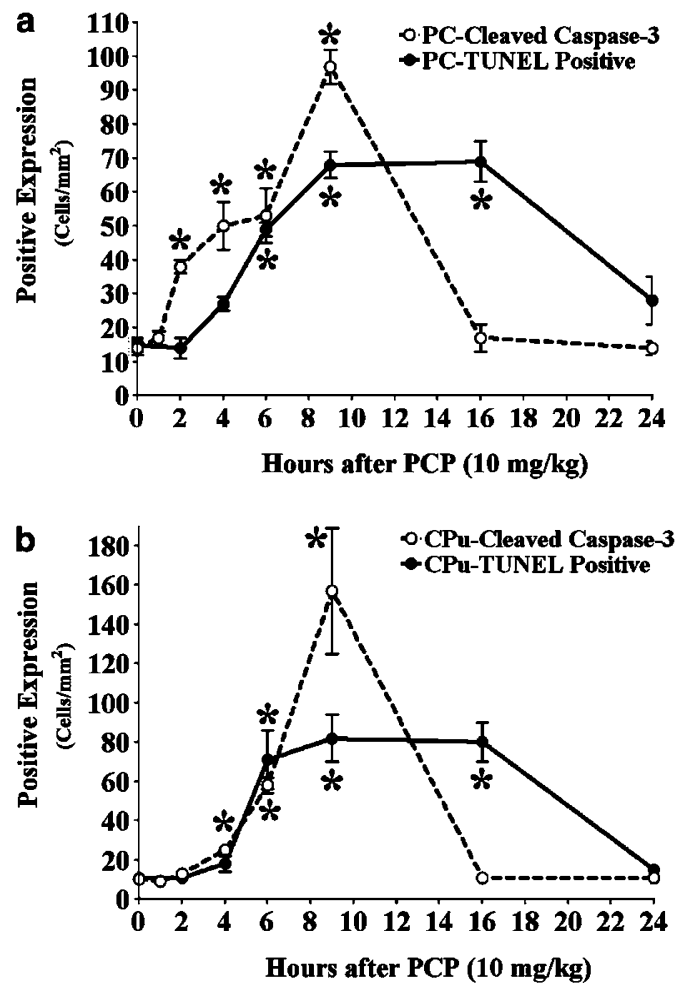

Figure 5 Cleaved caspase-3-IR precedes TUNEL staining following PCP $(10 \mathrm{mg} / \mathrm{kg})$ administration. In parietal cortex (a), significant caspase-3 activation appeared at $2 \mathrm{~h}$, about $4 \mathrm{~h}$ early than TUNEL positivity, which was significantly increased at $6 \mathrm{~h}$ after PCP exposure. In striatum (b), significant caspase-3 activation appeared at $4 \mathrm{~h}$, about $2 \mathrm{~h}$ early than neuronal death which increased $6 \mathrm{~h}$ after PCP exposure. $* p<0.05$ (oneway ANOVA, with Dunnett's post hoc test).
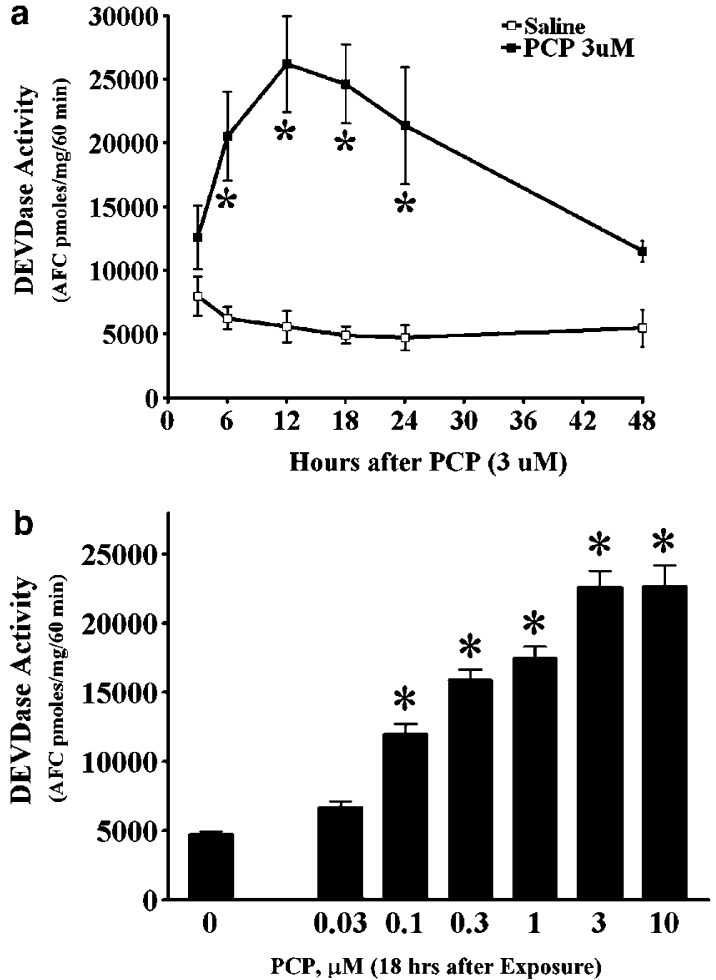

Figure 6 (a) Time-dependent increase in caspase-3 activity as measured in whole slices treated with saline or PCP $(3 \mu \mathrm{M})$ at DIVII (DIV0 = P2). $* p<0.05$ (unpaired t-test vs saline control at each time point). (b) Dosedependent increase in caspase-3 activity $18 \mathrm{~h}$ after saline or exposure to PCP at 0.03, 0. I, 0.3, I, 3, or I $0 \mu \mathrm{M}$ on DIVII. * $p<0.05\left(F_{6,40}=10.6\right.$, oneway ANOVA, with Dunnett's post hoc test).
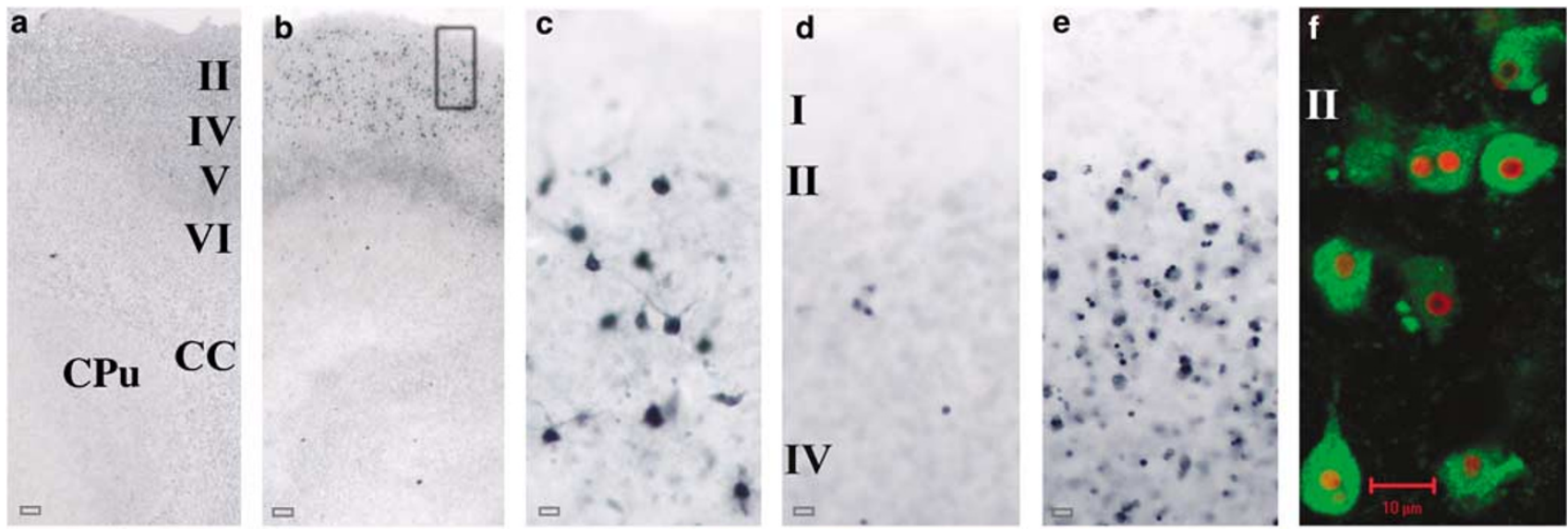

Figure 7 Caspase-3 activation accompanied by neuronal death (TUNEL-positive) in parietal cortex of cultured organotypic slices $12 \mathrm{~h}$ after saline or PCP $(3 \mu \mathrm{M})$ treatment at DIVII (DIV0 = P2). After saline exposure, only a few scattered neurons were positive for cleaved caspase-3-IR neurons (a), but many were apparent in layers II-IV following exposure to PCP (b and c). Similarly, only a few TUNEL positive neurons were observed after saline exposure in the layers II-IV of the parietal cortex (d), but many TUNEL-positive neurons were found I $2 \mathrm{~h}$ after PCP ( $3 \mu \mathrm{M})$ (e). Coexpression of TUNEL (red) and cleaved caspase-3 (green) was observed in the same neurons in parietal II-IV layers $12 \mathrm{~h}$ after addition of PCP (3 $\mu \mathrm{M})(\mathrm{f})$. Bar $=100 \mu$ (a and b) or I0 $\mu$ (c-f).

neurons showed typical neuronal structures, such as axons and dendrites. In cortical layers II-IV, TUNEL-positive labeling was very scattered and sparse in untreated slices (Figure 7d), but was much more extensively expressed in PCP-exposed slices (Figure 7e). These TUNEL-positive cells showed the clumped nuclear chromatin pattern typical of cells dying by apoptosis similar to that found in cortical layers II-IV of P7 rat brains after PCP injection (Figure 3ac). As shown in Figure 7f, immunofluorescent multiplelabeling demonstrated that most of the neurons positive for 

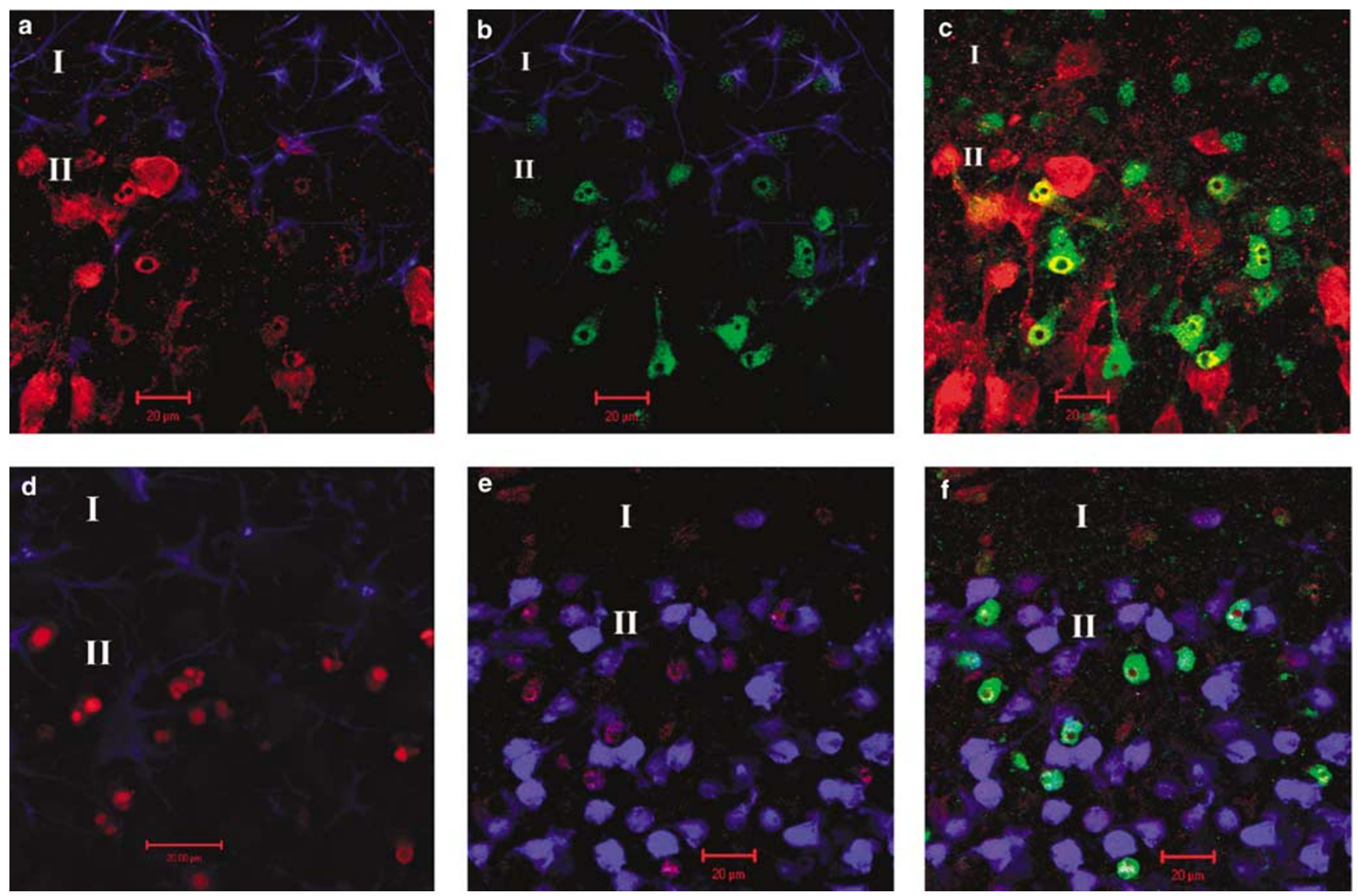

Figure 8 Immunofluorescence multiple-labeling of parietal cortical layers I-II of DIVII (DIV0 = P2) organotypic slices I $2 \mathrm{~h}$ after PCP $(3 \mu \mathrm{M})$ exposure (a-f). (a, b, and c) were taken from the same field: (a), NeuN-positive neurons (red) and GFAP-positive glial cells (blue); (b), cleaved caspase-3-IR neurons (green) showing no coexpression with GFAP (blue); (c), cleaved caspase-3-IR staining (green) coexpressed with NeuN-positive staining (red) in single neurons yielding a yellowish color. (d), TUNEL-positive nuclei (red) and glial cells (blue) showing little or no overlap. (e and f) were obtained from the same field: (e), TUNEL-positive staining (red) coexpressed with NeuN-positive staining (blue) in single neurons yielding a purple in color; ( $f$ ), TUNEL-positive nuclei (red) and cleaved caspase-3 positive cytoplasm (green) in NeuN-positive neurons (blue). Bars $=20 \mu$.

cleaved caspase-3 (green, cytoplasm) were also positive for TUNEL labeling (red, nuclei) in cortical layers II-IV $12 \mathrm{~h}$ after PCP exposure at DIV10 (DIV0 = P2). In these slices, neuronal nuclei never showed cleaved caspase-3 (Figures $7 f$, $8 \mathrm{~b}, \mathrm{c}$ and $\mathrm{f}$ ).

As shown in Figure 8, immunofluorescent multiplelabeling of neurons and glia with NeuN and GFAP, respectively, showed that glia were distributed throughout all cortical layers. On the other hand, NeuN-positive neurons were sparse to absent in layer I, but were expressed in layer II and deeper layers of the parietal cortex of the cultured slices (Figure 8a). After $12 \mathrm{~h}$ of exposure to $3 \mu \mathrm{M}$ PCP on DIV11, cleaved caspase-3 was not coexpressed with GFAP-positive glial cells (Figure 8b), but caspase-3 (green) was colocalized extensively in NeuN (red)-positive neurons yielding a yellowish color in the cytoplasm, especially around the nucleus (Figure 8c). PCP-induced TUNEL positivity (red) was not found in GFAP-positive (blue) glial cells (Figure 8d), but was expressed in NeuN-positive neurons (blue, Figure 8e) and in neurons double-labeled with NeuN (blue) and cleaved caspase-3 (green, Figure 8f). Importantly, glial cells never were positive for either cleaved caspase-3 or TUNEL after either saline (data not shown) or PCP $(3 \mu \mathrm{M})$ treatment (Figure $8 \mathrm{~b}, \mathrm{~d}$ and e). These data demonstrate that exposure of the slices to PCP results in neuron-specific caspase-3 activation and cell death (TUNEL-positive) in cerebral cortical layers II-IV, which is very similar to what was observed in vivo following PCP administration.

\section{Time Course of Caspase-3 Activation and Neuronal Death in Cerebral Cortices of Cultured Organotypic Slices}

Quantitative image analysis of parietal layers II-IV of DIV11 organotypic slices revealed that PCP induced increases in cleaved caspase-3-IR neurons in time-dependent manner (Figure 9a), with the increase in immunoreactivity reaching significance at $4 \mathrm{~h}$ (4.5-fold), peaking at $12 \mathrm{~h}$ (eight-fold) and then decreasing gradually until finally reaching control levels $48 \mathrm{~h}$ after treatment. This increase was also dose-dependent and saturable (Figure 9b). For example, when cleaved caspase-3-IR was quantified $18 \mathrm{~h}$ after treatment, $0.3 \mu \mathrm{M}$ PCP caused a 4.5 -fold increase, and both 3 and $10 \mu \mathrm{M}$ PCP resulted in an approximate 6.2 -fold increase (Figure 9b). In layers II-IV of the parietal cortex, PCP also induced neuronal apoptosis (TUNEL positivity) in a time- and dose-dependent manner (Figure $9 \mathrm{c}$ and d). At $18 \mathrm{~h}$ after PCP treatment, TUNEL-positive neurons were increased by three-fold by $0.3 \mu \mathrm{M}, 11$-fold by $1 \mu \mathrm{M}, 23$-fold 
by $3 \mu \mathrm{M}$, and by $10 \mu \mathrm{M}$ (Figure $8 \mathrm{~d}$ ), thereby showing a similar saturation curve as observed with PCP-induced procaspase- 3 cleavage. TUNEL-positive staining increased significantly by $9 \mathrm{~h}$ (9.5-fold), peaked at $12 \mathrm{~h}$ (37-fold), and remained quite high after $24 \mathrm{~h}$ of treatment (eight-fold),
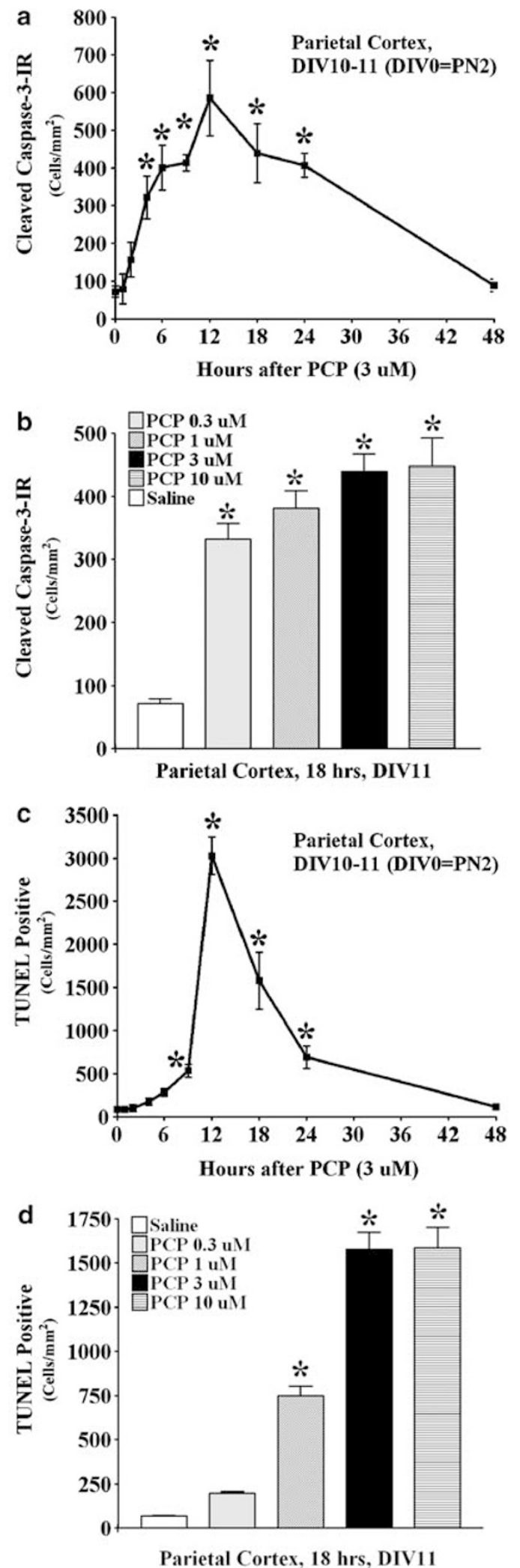

before returning to control levels by $48 \mathrm{~h}$. Thus, PCPinduced neuronal death as measured by TUNEL staining lagged behind the increase in cleaved caspase- 3 and was still prominent after the increase in caspase- 3 had significantly declined. These data are consistent with the hypothesis that procaspase-3 cleavage leads to apoptotic death in this preparation.

\section{Inhibition of Caspase-3 Activation Prevents PCP-Induced Neuronal Death in Cerebral Cortices of Cultured Organotypic Slices}

Selective caspase-3 inhibitors were used to further define the relationship between caspase- 3 activation and PCPinduced cell death. In the first series of experiments, slices were pretreated with Z-DEVD-fmk for $60 \mathrm{~min}$, followed by $3 \mu \mathrm{M}$ PCP for $18 \mathrm{~h}$, and then collected for TUNEL labeling and quantification. At $10 \mu \mathrm{M}, \mathrm{Z}$-DEVD-fmk pretreatment $\left(2339 \pm 558\right.$ TUNEL-positive cells $\left./ \mathrm{mm}^{2}\right)$ showed no significant effect when compared to controls $(2028 \pm 558$ TUNELpositive cells $/ \mathrm{mm}^{2}$ ). However, higher concentrations of Z-DEVD-fmk attenuated PCP-induced neuronal death in a dose-dependent manner. That is, 30,100 , and $300 \mu \mathrm{M} \mathrm{Z}$ DEVD-fmk reduced TUNEL-positive neurons to 1272 cells/ $\mathrm{mm}^{2}$ (63\%), 1043 cells $/ \mathrm{mm}^{2}$ (51\%), and 850 cells $/ \mathrm{mm}^{2}(42 \%$ of controls), respectively.

As Z-DEVD-fmk is not completely selective for caspase-3 and also is not completely cell permeable, we used Ac$\mathrm{A} \sim \mathrm{PDEVD}-\mathrm{CHO}$ which is known to be more cell permeable and to potently prevent ethanol-induced neuronal apoptosis in cultured cerebral cortical cells (Takadera and Ohyashiki, 2004). As illustrated in Figure 10, Ac-A PDEVD-CHO at $3 \mu \mathrm{M}$ completely blocked PCP-induced caspase- 3 activation (Figure $10 \mathrm{a}$ ) with an $\mathrm{IC}_{50}$ of $0.19 \pm 0.04 \mu \mathrm{M}$ and slope of $1.10 \pm 0.26$ (Figure 10b). Quantitative image analysis of parietal cortical layers II-IV revealed that Ac-A $\sim$ PDEVD$\mathrm{CHO}$ pretreatment prevented the majority of PCP-induced neuronal death in a dose-dependent manner (Figure 10c). That is, Ac-A $\sim$ PDEVD-CHO at $0.3,1$, and $3 \mu \mathrm{M}$ inhibited PCP $(3 \mu \mathrm{M})$-induced TUNEL-positive staining by 50,75 , and $87 \%$, respectively $(p<0.001$, one-way ANOVA, $\left.\mathrm{F}_{4,29}=27.45\right)$. The approximately equal $\mathrm{IC}_{50}$ values of 0.19 and $0.3 \mu \mathrm{M}$ against PCP-induced procaspase-3 cleavage and apoptosis in these slices is further support for the

Figure 9 Time and concentration-dependent activation of caspase-3 cleavage and TUNEL staining in layers II-IV of the parietal cortex induced by $3 \mu$ M PCP. (a), PCP induces significant increases in cleaved caspase-3-IR by $4 \mathrm{~h}$ which lasts for at least $24 \mathrm{~h}$, showing that PCP-induced caspase- 3 activation is similar to, but longer lasting than that in vivo. $* p<0.05$ $\left(F_{9,47}=9.45\right.$, one-way ANOVA, with Dunnett's post hoc test). (b) PCP induced dose-dependent increase in cleaved caspase-3-IR neuron in layers II-IV of parietal cortex at I $8 \mathrm{~h}$ after PCP exposure at DIVI I (DIV0 = P2). *p $<0.05\left(F_{4,23}=5.59\right.$, one-way ANOVA, with Dunnett's post hoc test). (c) Time-dependent increase in TUNEL-positive cells, showing a similar to, but longer lasting response than that in vivo. $* p<0.05\left(F_{9,94}=30.27\right.$, one-way ANOVA, with Dunnett's post hoc test). (d) Dose-dependent increase in TUNEL-positive cell number $18 \mathrm{~h}$ after PCP exposure. $* p<0.05$ $\left(F_{4,49}=17.99\right.$, one-way ANOVA, with Dunnett's post hoc test). Note that there was a significant increase in cleaved caspase-3-IR (a) earlier than TUNEL expression (c). 

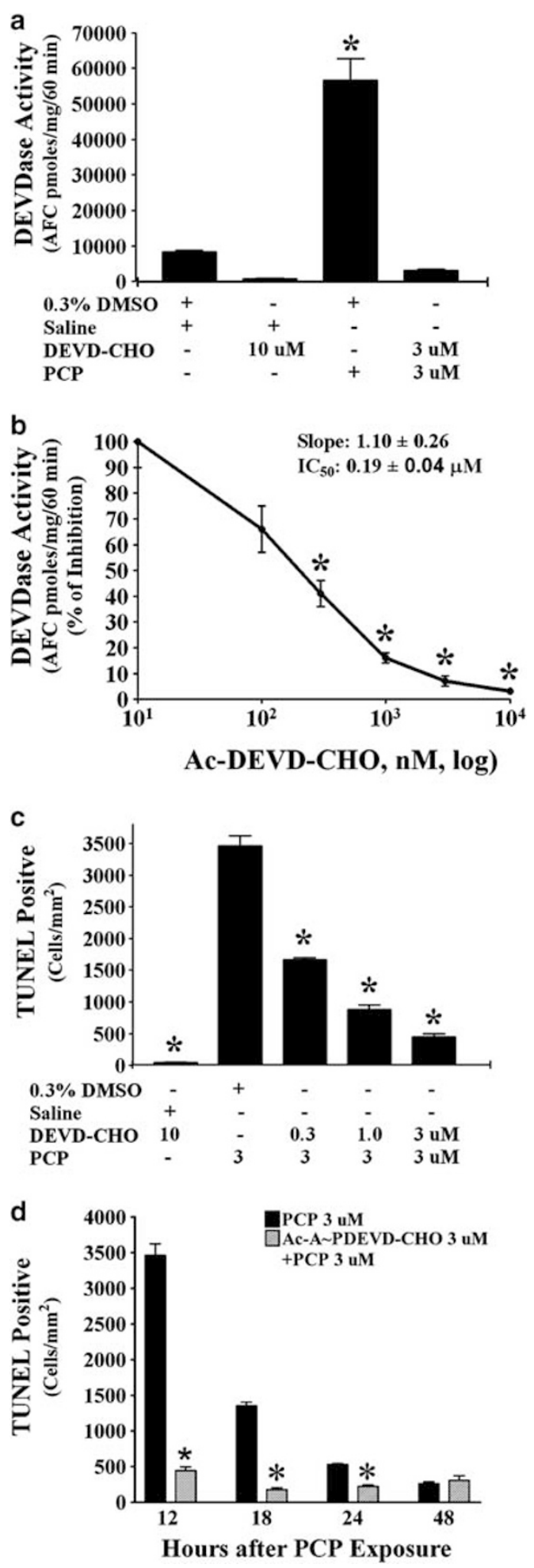

Figure 10 Effects of caspase- 3 inhibition on PCP $(3 \mu \mathrm{M})$-induced caspase-3 activity and TUNEL staining in vitro. (a) Pretreatment with $3 \mu \mathrm{M}$ Ac-A $\sim$ PDEVD-CHO almost completely prevented PCP-induced caspase-3 activation $9 \mathrm{~h}$ after exposure on DIVII. (b) Dose-response analysis of the inhibition curve by nonlinear regression revealed a slope of I.I and $I_{50}$ of $0.2 \mu \mathrm{M}$. (c) Ac-A $\sim$ PDEVD-CHO also inhibited TUNEL staining caused by $3 \mu \mathrm{M} P C P$, but it was somewhat less potent $\left(\mathrm{IC}_{50}\right.$ $\sim 0.3 \mu \mathrm{M}$ ). (d) Temporal analysis of the inhibition of TUNEL staining by $3 \mu \mathrm{M}$ Ac-A $\sim$ PDEVD-CHO. The magnitude of inhibition was $87 \%$ at $12 \mathrm{~h}$ and $18 \mathrm{~h}$, and $58 \%$ at $24 \mathrm{~h} .{ }^{*} p<0.05\left(\mathrm{~F}_{4,29}=27.45\right.$, one-way ANOVA, with Dunnett's post hoc test).

hypothesis that the majority of PCP-induced neuronal apoptosis is dependent upon procaspase- 3 cleavage.

Finally, to address the possibility that caspase- 3 inhibition may only delay, rather than actually prevent, neuronal death, we measured the number of TUNEL-positive neurons at $12,18,24$, and $48 \mathrm{~h}$ after PCP treatment in the absence and presence of Ac-A $\sim$ PDEVD-CHO. These data are shown in Figure 10, panel d. The number of TUNEL-positive cells in the presence of the inhibitor at 18,24 , and $48 \mathrm{~h}$ is less the number found at $12 \mathrm{~h}$. Thus, there does not appear to be delayed death in the presence of the caspase- 3 inhibitor. The decay in the apparent number of TUNEL-positive cells with time is in keeping with the expected removal of apoptotic cells. Further, the degree of inhibition by Ac-A PDEVD-CHO at 12 and $18 \mathrm{~h}$ is identical (87\%), again suggesting that the inhibitor prevents cell death over this interval, rather than delaying it. The magnitude of the inhibition decreases somewhat at $24 \mathrm{~h}(58 \%)$ and is not evident by $48 \mathrm{~h}$. This is most likely due to the degradation of the peptide inhibitor, but it could suggest that a very small portion of the total number of cells apparently protected by the inhibitor do indeed go on to die. If the inhibitor is expected to have $87 \%$ protection at the later time points, one can calculate the total number of cells that go on to die in a caspase-3-independent manner at 24 and $48 \mathrm{~h}$. This number appears to be about $5 \%$ of the total at $24 \mathrm{~h}$, and $8 \%$ of total at $48 \mathrm{~h}$ that die by a caspase-3-independent mechanism.

\section{DISCUSSION}

Although Adams et al (2004) reported that cleaved caspase3 was expressed in the developing somatosensory thalamus after PCP administration, this is the first detailed report of the relationship between PCP-induced apoptosis and caspase- 3 activation in the developing brain. Further, the establishment of PCP-induced apoptosis in a corticostriatal slice model allowed the use of selective peptide-based caspase- 3 inhibitors to show that caspase- 3 activation is requisite for PCP-induced cortical apoptosis. These data also show that acute PCP administration to P7 rats induces a regionally selective and time-dependent caspase- 3 enzymatic activation and coincident expression of cleaved caspase-3-IR. Quantitative analysis of cleaved caspase-3 and TUNEL staining in the same regions and subregions demonstrated that PCP-induced caspase- 3 activation and neuronal death had a similar dose dependence. Further, cleaved caspase-3-IR neurons were distributed in the same brain regions and subregions as both silver-positive and TUNEL-positive neurons, demonstrating that PCP-induced neuronal death or degeneration is accompanied by caspase3 activation. A $Z$-axis scan (Figure $4 \mathrm{f}$ ) and 3D reconstruction (available upon request) of neuron dual labeling confirmed that cleaved caspase- 3 and TUNEL were coexpressed in the same neurons in all brain regions and subregions studied: fragmented TUNEL-positive nuclei embedded in cleaved caspase-3-IR cytoplasm with projections, thereby demonstrating that PCP-induced caspase-3 activation is related spatially to neuronal death. Analysis of the temporal profile revealed that cleaved caspase-3-IR neurons were expressed about $2-4 \mathrm{~h}$ prior to TUNEL- 
positive staining. This is consistent with the hypothesis that cleavage of procaspase- 3 to an active form plays a causative role in PCP-induced neuronal death. This conclusion was validated and extended by both bright-field and immunofluorescence multiple labeling, demonstrating that caspase3 activation preceded TUNEL staining by about $3 \mathrm{~h}$. Further, this approach demonstrates that caspase-3 cleavage activity persists for several hours, but diminishes prior to complete degeneration of the cell. The relationship between caspase-3 activation and PCP-induced neuronal death observed in vivo was also found in cortical layers II-IV of organotypic slices. Furthermore, the majority of PCP-induced neuronal death in vitro was blocked (85\%) by Ac-A PDEVD-CHO, a cell-permeable caspase- 3 selective inhibitor. Based on these data, we conclude that caspase- 3 activation plays a pivotal role in PCP-induced death in developing neurons and therefore PCP induces developing neuron death mainly and primarily via apoptotic mechanism. This conclusion is in line with earlier study (Kuida et al, 1996) supporting caspase- 3 activation as the most important executioner of neuronal apoptosis during brain development.

Our conclusion is also consistent with previous studies demonstrating caspase-3 activation during brain development after other NMDAR antagonists including MK-801, ketamine, CGP 3955, and even ethanol. Hwang et al (1999) and Takadera et al (1999) found that in dissociated cortical cultures, exposure of MK- 801 for $48 \mathrm{~h}$ induced caspase- 3 activation and $\mathrm{LDH}$ release which was attenuated by $\mathrm{z}$ VAD-fmk (a broad caspase inhibitor) or Ac-DEVD-CHO (a caspase-3 inhibitor). Monti and Contestabile (2000) showed CGP 3955, a competitive NMDAR antagonist activated caspase- 3 and eliminated cerebellar granule neurons in the rat cerebellum in vivo. Yoon et al (2003) reported that in a mouse cortical cell culture preparation, glutamate receptor blockade with a combination of MK-801 and CNQX (MK801/CNQX) induced caspase-3 activation and cell death, which was significantly reduced by $100 \mu \mathrm{M}$ of zVAD-fmk. Caspase- 3 activation has also been reported after repeated doses of $20 \mathrm{mg} / \mathrm{kg}$ ketamine (Scallet et al, 2004) or a single dose of $40 \mathrm{mg} / \mathrm{kg}$ ketamine (Young et al, 2005). After ethanol exposure, cultured cortical neurons showed caspase- 3 activation and apoptosis, which was prevented by the caspase-3 inhibitor Ac-A $\sim$ PDEVD-CHO (Takadera and Ohyashiki, 2004).

However, rodents treated with ethanol during brain development showed that caspase-3 activation is not required for ethanol-induced neuronal death (Young et al, 2005; Nowoslawski et al, 2005). This was surprising in light of our preliminary experiments with PCP and is one of the reasons for this detailed study of PCP neurotoxicity. Although ethanol also potentiates GABAergic transmission, much of its neurotoxicity is believed to be mediated by blockade of NMDARs (Hoffman et al, 1989; Lovinger et al, 1989; Ikonomidou et al, 2000; Olney, 2002; Olney et al, 2002). After administration of ethanol to P7 mice, apoptosis occurred with widespread caspase- 3 activation in wild-type brains (Olney et al, 2002), but, surprisingly, also occurred in caspase-3-deficient brains (caspase-3 $3^{-1-}$ ) (Young et al, 2005). Although the GABA-mimetic properties of ethanol could qualitatively alter the mechanism by which ethanol causes cell death, it is important to point out that apoptotic neurodegeneration induced by ethanol, MK-801, and phenobarbital (a positive GABA receptor modulator) all have the same ultrastructural appearance and all appear very similar to physiological cell death (Ikonomidou et al, 2000). Despite this similarity, the pattern of degeneration induced by phenobarbital differed in several major aspects from MK-801. First, although MK-801 and phenobarbital both cause death of cortical neurons in the superficial layers of the cortex, the middle cortical layers are prominently affected by phenobarbital, but are relatively spared by MK-801. Second, in the anterior thalamus, MK-801 affects the laterodorsal, anteroventral, and anteromedial nuclei, but not the anterodorsal nucleus, whereas phenobarbital prominently affects the laterodorsal and anterodorsal nuclei, but almost entirely spares the anteroventral and anteromedial nuclei. Thus, the ethanol pattern resembles a combination of the MK-801 and phenobarbital patterns (Ikonomidou et al, 2000). The present study also demonstrated that in the cerebral cortices, PCP-induced expression of cleaved caspase- 3 and positive TUNEL staining were confined to layers II-IV, especially II (Figures 2 and 3), which is very different from that after ethanol administration (Ikonomidou et al, 2000). In addition, although caspase-3-IR was found in neuronal soma and projections after both PCP and ethanol, caspase-3-IR in neuronal nuclei was observed after ethanol exposure (Young et al, 2003), but not after PCP treatment (Figures $4 \mathrm{f}, 7 \mathrm{f}$ and $8 \mathrm{~b}$ ). The difference between NMDA antagonists (PCP, MK-801) and ethanol may result from somewhat different mechanisms of apoptosis. This may explain why caspase- 3 activation appears to play a necessary role in PCP-induced neuronal death, but not in ethanol-induced neurodegeneration.

Previous studies from this lab reported that an increase in the NMDAR NR1 subunit mRNA was accompanied by selective cell death in frontal cortex $24 \mathrm{~h}$ after subchronic PCP administration on P7, P9, and P11 (Wang et al, 2001). Increases in cortical NR1 and NR2B polypeptides were reported following acute administration on P7 (Anastasio and Johnson, unpublished observation). Additionally, in a quite different corticostriatal slice preparation, cortical neuronal death was accompanied by upregulation of NR1 and NR2A subunits after PCP exposure for $48 \mathrm{~h}$ (and a $24 \mathrm{~h}$ washout) (Wang et al, 2005). Further, coincubation of PCP with either NR1 or NR2A antisense significantly reduced PCP-induced apoptosis (Wang et al, 2005). These data suggest that NMDAR upregulation may contribute to PCPinduced apoptosis. This is inconsistent with the widely accepted concept that NMDAR activation induces necrotic neuronal death in developing mouse brain after NMDAR activation (Olney et al, 1971; Choi, 1985). However, there is also substantial data suggesting that low-level NMDA receptor activation can also cause apoptotic death (Ankarcrona et al, 1995; Hardingham and Bading, 2003; Meli et al, 2004). Thus, it appears possible that both a decrease in intracellular calcium as well as an increase in NMDA receptor function could play a role in PCP-induced cell death, depending on the duration of the blockade and the time course of the receptor upregulation as well as factors such as intracellular and mitochondrial calcium that influence the redox state of the cellular milieu, nitric oxide and superoxide production, nuclear NF- $\kappa \mathrm{B}$, induction of proapoptic factors such as Bax and mitochondrial cytochrome $c$ release (Wang et al, 2001; McInnis et al, 2002), 
and other factors known to promote the cleavage/activation of caspase-3. As PCP $(5 \mathrm{mg} / \mathrm{kg})$ has been reported to induce a 2-3-fold increase in extracellular glutamate levels (Adams and Moghaddam, 1998), it seemed possible that activation of NMDARs (particularly considering that they may be upregulated) may play a role in PCP-induced cell death in this preparation. However, although $3 \mu \mathrm{M}$ PCP activated caspase-3 (Figures 6a and 7c), NMDA (1-100 $\mu \mathrm{M})$ did not induce caspase- 3 activation in this preparation following $12 \mathrm{~h}$ of exposure (unpublished observation). Thus, it seems unlikely that NMDAR upregulation plays a critical role in PCP-induced apoptosis in this preparation. However, we cannot rule out the possibility that NMDAR upregulation may play a role in caspase-3-independent cell death, possibly through necrotic mechanisms. It should also be acknowledged that it is possible that there are regional differences in the mechanism of cell death following PCP. Direct comparison of our quantitative TUNEL data presented here in Table 2 with our previous quantification of silver staining in Table 1 in Wang and Johnson (2005) shows similar values in all regions $6 \mathrm{~h}$ after PCP administration. However, at 9, 16, and $24 \mathrm{~h}$ after PCP administration, there are significantly more silver-positive cells than TUNEL-positive cells, particularly in the subiculum and thalamus. Thus, in these regions at longer times after PCP, the higher number of silver-positive neurons may well be due to necrotic death, and NMDAR upregulation could play a more substantial role in these regions, although this remains speculative at this time.

The mechanisms that lead to caspase-3 activation following NMDAR blockade are not yet well understood. Although not the purpose of the present study, previous studies have proposed several intermediate pathways. In addition to the mechanisms involving activation of NF- $\kappa \mathrm{B}$, Bax synthesis and translocation to outer mitochondrial membrane, mitochondrial cytochrome $c$ release, and caspase activation, the initial mechanism leading to Bax translocation is not yet clear. A deficit in intracellular calcium after NMDAR blockade has been reported to induce caspase-3 activation in cortical cell cultures after exposure to an MK-801/CNQX combination (Yoon et al, 2003). In this preparation, either reduction of extracellular calcium or the exposure to BAPTA-AM, an intracellular calcium chelator, both induced caspase- 3 activation. Earlier, Takadera et al (1999a) reported that the addition of MK-801 to dissociated neuronal cultures causes an almost immediate decrease in intracellular calcium concentration from about 100 to $50 \mathrm{nM}$ (see also Turner et al, 2002). The latter authors also reported that increasing intracellular calcium with thapsigargin or ionomycin was able to antagonize MK-801induced death measured $24 \mathrm{~h}$ after application. Thus, it seems likely that reduction of intracellular calcium is critical to NMDA antagonist-induced cell death in dissociated neuronal culture. However, whether this is the critical mechanism in slices or in vivo is not yet known. Nevertheless, the MK-801-induced intracellular calcium deficit may be the initial factor triggering a prosurvival pathway being involved in the pathogenesis of NMDAR blockade-induced developing neuron death. Hansen et al (2004) found that in brain regions that display severe apoptotic neurodegeneration, MK-801 impaired activity of extracellular signal-regulated kinase1/2 (ERK1/2) and re- duced levels of phosphorylated cAMP-responsive elementbinding protein (CREB), which are important components of the ERK1/2 signaling pathway for cell survival. The impaired ERK1/2 and CREB activity were temporally paralleled by sustained depletion of neurotrophin expression, particularly brain-derived neurotrophic factor (BDNF), and BDNF supplementation fully prevented MK801-induced neurotoxicity in immature neuronal cultures. In addition, transgenic constitutive activation of Ras, a component of the ERK1/2 signaling pathway for cell survival, was associated with marked protection against MK-801-induced apoptotic neuronal death. As certain neurotrophins exert their neuroprotective powers through the activation of CREB, coadministration of 17 betaestradiol and MK-801 to P7 rats also ameliorated MK-801 neurotoxicity possibly by increasing levels of phosphorylated ERK1/2 and AKT (Asimiadou et al, 2005). Coadministration of recombinant EPO and MK-801 conferred 50\% neuroprotection with partial restoration of MK-801-induced reduction of BDNF and glial cell line-derived neurotrophic factor (GDNF) mRNA, as well as prevention of the decrease in phosphorylation levels of ERK1/2 and Akt (Dzietko et al, 2004). However, the relationship between the proapoptotic and prosurvival mechanisms has not yet been defined at present time.

Our interest in the mechanism of PCP-induced cell death was initiated by the observations that PCP administration produced symptoms of schizophrenia in adults (Luby et al, 1959; Cosgrove and Newell, 1991; Javitt and Zukin, 1991) and that the etiology of schizophrenia may involve an alteration in normal development that may also include the death of a subset of cortical neurons during early development (Lewis, 2000). This laboratory has demonstrated that administration of PCP on P7, 9, and 11 is associated with deficits in pre-pulse inhibition as well as in short-term working memory (Wang et al, 2001; Wiley et al, 2003). Recent studies from other laboratories have also reported that transient NMDAR blockade during brain development caused behavioral, structural, and molecular abnormalities in adulthood (Harris et al, 2003; Stefani and Moghaddam, 2005). Additional validation of this model comes from a comparison of PCP-induced neurotoxicity and postmortem schizophrenic brains. Studies of these brains have documented significant layer-specific reductions in the density of neuronal subpopulations including interneurons in layer II of prefrontal cortex and in layers IIVI of the anterior cingulate cortex (Benes et al, 1991), as well as pyramidal neurons in layer IV of anterior cingulate cortex (Benes et al, 2001), indicating that these subregions may be critical in schizophrenia. The present study demonstrated that single dose PCP treatment of postnatal rats induced apoptosis in similar regions of the developing rat brain including striatum, thalamus, hippocampus, and cortices of cingulate, frontal, retrosplenial, and parietal cortex, with specificity for layers II-IV. These similarities suggest that a clear understanding of the mechanisms by which PCP causes selective neurotoxicity in these rat brain regions may yield insights that will improve the treatment of schizophrenia. This study also provides evidence that the corticostriatal slice preparation is a useful model in which to investigate the mechanisms of PCP-induced cell death, particularly in cortical layers II-IV. This model should 
allow detailed study of the intermediate biochemical pathways that lie between NMDAR blockade and activation of the caspase cascade, and in doing so, may lead to new therapeutic strategies for the treatment of schizophrenia.

\section{ACKNOWLEDGEMENTS}

We are grateful to Dr Leoncio A Vergara for his help with confocal microscopy and Dr Gang Lei for his comments in preparing this manuscript. We also thank Ms Tiffany E Springsted for her assistance. This work was supported by grants MH63871 and DA02073 from the US Department of Health and Human Services.

\section{REFERENCES}

Adams B, Moghaddam B (1998). Corticolimbic dopamine neurotransmission is temporally dissociated from the cognitive and locomotor effects of phencyclidine. J Neurosci 18: 5545-5554.

Adams SM, de Rivero Vaccari JC, Corriveau RA (2004). Pronounced cell death in the absence of NMDA receptors in the developing somatosensory thalamus. J Neurosci 24: 9441-9450.

Ankarcrona M, Dypbukt JM, Bonfoco E, Zhivotovsky EB, Orrenius S, Lipton SB et al (1995). Glutamate-induced neuronal death: a succession of necrosis or apoptosis depending on mitochondrial function. Neuron 15: 961-973.

Asimiadou S, Bittigau P, Felderhoff-Mueser U, Manthey D, Sifringer M, Pesditschek $S$ et al (2005). Protection with estradiol in developmental models of apoptotic neurodegeneration. Ann Neurol 58: 266-276.

Benes FM, Berretta S (2001). GABAergic interneurons: implications for understanding schizophrenia and bipolar disorder. Neuropsychopharmacology 25: 1-27.

Benes FM, McSparren J, Bird ED, SanGiovanni JP, Vincent SL (1991). Deficits in small interneurons in prefrontal and cingulate cortices of schizophrenic and schizoaffective patients. Arch Gen Psychiatry 48: 996-1001.

Benes FM, Vincent SL, Todtenkopf M (2001). The density of pyramidal and nonpyramidal neurons in anterior cingulate cortex of schizophrenic and bipolar subjects. Biol Psychiatry 50: $395-406$.

Carlsen J, De Olmos JS (1981). A modified cupric-silver technique for the impregnation of degenerating neurons and their processes. Brain Res 208: 426-431.

Choi DW (1985). Glutamate neurotoxicity in cortical cell culture is calcium dependent. Neuroscience Lett 58: 293-297.

Clinton SM, Meador-Woodruff JH (2004). Thalamic dysfunction in schizophrenia: neurochemical, neuropathological, and in vivo imaging abnormalities. Schizophr Res 69: 237-253.

Cohen GM (1997). Caspases: the executioners of apoptosis. Biochem J 326: 1-16.

Cosgrove J, Newell TG (1991). Recovery of neuropsychological functions during reduction in use of phencyclidine. J Clin Psychiatry 47: 159-169.

Dzietko M, Felderhoff-Mueser U, Sifringer M, Krutz B, Bittigau P, Thor F et al (2004). Erythropoietin protects the developing brain against $N$-methyl-D-aspartate receptor antagonist neurotoxicity. Neurobiol Dis 15: 177-187.

Fischer U, Jänicke RU, Schulze-Osthoff K (2003). Many cuts to ruin: a comprehensive update of caspase substrates. Cell Death Differ 10: 76-100.

Fiske BK, Brunjes PC (2001). NMDA receptor regulation of cell death in the rat olfactory bulb. J Neurobiol 47: 223-232.

Fix AS, Horn JW, Wightman KA, Johnson CA, Long GG, Storts RW et al (1993). Neuronal vacuolization and necrosis induced by the noncompetitive $N$-methyl-D-aspartate (NMDA) antagonist $\mathrm{MK}(+) 801$ (dizocilpine maleate): a light and electron microscopic evaluation of the rat retrosplenial cortex. Exp Neurol 123: 204-215.

Gavrieli Y, Sherman Y, Ben-Sasson SA (1992). Identification of programmed cell death in situ via specific labeling of nuclear DNA fragmentation. J Cell Biol 119: 493-501.

Gould E, Cameron HA, McEwen BS (1994). Blockade of NMDA receptors increases cell death and birth in the developing rat dentate gyrus. J Comp Neurol 340: 551-565.

Hansen HH, Briem T, Dzietko M, Sifringer M, Voss A, Rzeski W et al (2004). Mechanisms leading to disseminated apoptosis following NMDA receptor blockade in the developing rat brain. Neurobiol Dis 16: 440-453.

Hardingham GE, Bading H (2003). The Yin and Yang of NMDA receptor signaling. Trends Neurosci 26: 81-89.

Harris LW, Sharp T, Gartlon J, Jones DN, Harrison PJ (2003). Long-term behavioral, molecular and morphological effects of neonatal NMDA receptor antagonism. Eur J Neurosci 18: 17061710.

Harrison PJ, Weinberger DR (2005). Schizophrenia genes, gene expression, and neuropathology: on the matter of their convergence. Mol Psychiatry 10: 40-68.

Hoffman PL, Rabe CS, Moses F, Tabakoff B (1989). N-methyl-Daspartate receptors and ethanol: inhibition of calcium flux and cyclic GMP production. J Neurochem 52: 1937-1940.

$\mathrm{Hu}$ BR, Liu CL, Ouyang Y, Blomgren K, Siesjo BK (2000). Involvement of caspase-3 in cell death after hypoxia-ischemia declines during brain maturation. J Cereb Blood Flow Metab 20: 1294-1300.

Hwang JY, Kim YH, Ahn YH, Wie MB, Koh JY (1999). N-Methyl-Daspartate receptor blockade induces neuronal apoptosis in cortical culture. Exp Neurol 159: 124-130.

Ikonomidou C, Bittigau P, Ishimaru M, Wozniak DF, Koch C, Genz $\mathrm{K}$ et al (2000). Ethanol-induced apoptotic neurodegeneration and fetal alcohol syndrome. Science 287: 1056-1060.

Ikonomidou C, Bosch F, Miksa M, Bittigau P, Vockler J, Dikranian $\mathrm{K}$ et al (1999). Blockade of NMDA receptors and apoptotic neurodegeneration in the developing brain. Science 283: 70-74.

Jarskog LF, Glantz LA, Gilmore JH, Lieberman JA (2005). Apoptotic mechanisms in the pathophysiology of schizophrenia. Prog Neuro-Psychopharmacol Biol Psych 29: 846-858.

Javitt DC, Zukin SR (1991). Recent advances in the phencyclidine model of schizophrenia. Am J Psychiatry 148: 1301-1308.

Kasai K, Iwanami A, Yamasue H, Kuroki N, Nakagome K, Fukuda $M$ (2002). Neuroanatomy and neurophysiology in schizophrenia. Neurosci Res 43: 93-110.

Krystal JH, D'Souza DC, Mathalon D, Perry E, Belger A, Hoffman R (2003). NMDA receptor antagonist effects, cortical glutamatergic function, and schizophrenia: toward a paradigm shift in medication development. Psychopharmacology (Berl) 169: 215-233.

Kudryashov IE, Onufriev MV, Kudryashova IV, Gulyaeva NV (2001). Periods of postnatal maturation of hippocampus: synaptic modifications and neuronal disconnection. Brain Res Dev Brain Res 132: 113-120.

Kuida K, Zheng TS, Na S, Kuan C, Yang D, Karasuyama H et al (1996). Decreased apoptosis in the brain and premature lethality in CPP32-deficient mice. Nature 384: 368-372.

Lewis DA (2000). GABAergic local circuit neurons and prefrontal cortical dysfunction in schizophrenia. Brain Res Brain Res Rev 31: $270-276$

Lipska BK (2004). Using animal models to test a neurodevelopmental hypothesis of schizophrenia. J Psychiatry Neurosci 29: 282-286.

Lodge D, Johnson KM (1990). Noncompetitive excitatory amino acid receptor antagonists. Trends Pharmacol Sci 11: 81-86. 
Lovinger DM, White G, Weight FF (1989). Ethanol inhibits NMDA-activated ion current in hippocampal neurons. Science 243: 1721-1724.

Luby ED, Cohen BD, Rosenbaum G, Gottlieb JS, Kelley R (1959). Study of a new schizophrenomimetic drug; sernyl. AMA Arch Neurol Psychiatry 81: 363-369.

McInnis J, Wang C, Anastasio N, Hultman M, Ye Y-P, Salvemini D et al (2002). The role of superoxide and NF- $\kappa \mathrm{B}$ signaling in $\mathrm{N}-$ methyl-D-aspartate-induced necrosis and apoptosis. J Pharmacol Exp Ther 301: 478-487.

Meli E, Pangallo M, Picca R, Baronti R, Moroni F, PellegriniGiampietro D (2004). Differential role of poly(ADP-ribose) polymerase-1 in apoptotic and necrotic neuronal death induced by mild or intense NMDA exposure in vitro. Mol Cell Neurosci 25: $172-180$.

Monti B, Contestabile A (2000). Blockade of the NMDA receptor increases developmental apoptotic elimination of granule neurons and activates caspases in the rat cerebellum. Eur $J$ Neurosci 12: 3117-3123.

Noraberg J, Kristensen BW, Zimmer J (1999). Markers for neuronal degeneration in organotypic slice cultures. Brain Res Brain Res Protoc 3: 278-290.

Nowoslawski L, Klocke BJ, Roth KA (2005). Molecular regulation of acute ethanol-induced neuron apoptosis. J Neuropathol Exp Neurol 64: 490-497.

Olney JW (2002). New insights and new issues in developmental neurotoxicology. Neurotoxicology 23: 659-668.

Olney JW, Farber NB (1995). Glutamate receptor dysfunction and schizophrenia. Arch Gen Psychiatry 52: 998-1007.

Olney JW, Ho OL, Rhee V (1971). Cytotoxic effects of acidic and sulphur containing amino acids on the infant mouse central nervous system. Exp Brain Res 14: 61-76.

Olney JW, Labruyere J, Price MT (1989). Pathological changes induced in cerebrocortical neurons by phencyclidine and related drugs. Science 244: 1360-1362.

Olney JW, Newcomer JW, Farber NB (1999). NMDA receptor hypofunction model of schizophrenia. J Psychiatric Res 33: 523-533.

Olney JW, Tenkova T, Dikranian K, Muglia LJ, Jermakowicz WJ, D'Sa C et al (2002). Ethanol-induced caspase-3 activation in the in vivo developing mouse brain. Neurobiol Dis 9: 205-219.

Paxinos G, Watson C (1998). The Rat Brain in Stereotaxic Coordinates, 4th edn. Academic Press, Inc.: San Diego, California, USA (Plate 10-14, 81-82).

Rapoport JL, Addington AM, Frangou S, Psych MR (2005). The neurodevelopmental model of schizophrenia: update 2005. Mol Psychiatry 10: 434-449.

Sattler R, Tymianski M (2001). Molecular mechanisms of glutamate receptor-mediated excitotoxic neuronal cell death. Mol Neurobiol 24: 107-129.

Scallet AC, Schmued LC, Slikker W, Grunberg N, Faustino PJ, Davis H et al (2004). Developmental neurotoxicity of ketamine: morphometric confirmation, exposure parameters, and multiple fluorescent labeling of apoptotic neurons. Toxicol Sci 81: 364-370.

Sharp FR, Butman M, Aardalen K, Nickolenko J, Nakki R, Massa SM et al (1994). Neuronal injury produced by NMDA antagonists can be detected using heat shock proteins and can be blocked with antipsychotics. Psychopharmacol Bull 30: 555-560.
Sherwood NM, Timiras PS (1970). A Stereotaxic Atlas of the Developing Rat Brain. University of California Press: Berkeley.

Smith PK, Krohn RI, Hermanson GT, Mallia AK, Gartner FH, Provenzano MD et al (1985). Measurement of protein using bicinchoninic acid. Anal Biochem 150: 76-85.

Stefani MR, Moghaddam B (2005). Transient N-methyl-D-aspartate receptor blockade in early development causes lasting cognitive deficits relevant to schizophrenia. Biol Psychiatry 57: 433-436.

Stefanis L, Park DS, Yan CY, Farinelli SE, Troy CM, Shelanski ML et al (1996). Induction of CPP32-like activity in PC12 by withdrawal of trophic support. Dissociation from apoptosis. J Biol Chem 271: 30663-30671.

Stoppini L, Buchs PA, Muller D (1991). A simple method for organotypic cultures of nervous tissue. J Neurosci Methods 37: 173-182.

Takadera T, Matsuda I, Ohyashiki T (1999). Apoptotic cell death and caspase- 3 activation induced by $N$-methyl-D-aspartate receptor antagonists and their prevention by insulin-like growth factor I. J Neurochem 73: 548-556.

Takadera T, Ohyashiki T (2004). Glycogen synthase kinase-3 inhibitors prevent caspase-dependent apoptosis induced by ethanol in cultured rat cortical neurons. Eur J Pharmacol 499: 239-245.

Turner CP, Pulciani D, Rivkees SA (2002). Reduction in intracellular calcium levels induces injury in developing neurons. Exp Neurol 178: 21-32.

Wang C, Fridley J, Johnson KM (2005). The role of NMDA receptor upregulation in phencyclidine-induced cortical apoptosis in organotypic culture. Biochem Pharmacol 69: 1373-1383.

Wang C, McInnis J, Ross-Sanchez M, Shinnick-Gallagher P, Wiley JL, Johnson KM (2001). Long-term behavioral and neurodegenerative effects of postnatal phencyclidine administration: implications for schizophrenia. Neuroscience 107: 535-550.

Wang CZ, Johnson KM (2005). Differential effects of acute and subchronic administration on phencyclidine-induced neurodegeneration in the postnatal rat. J Neurosci Res 81: 284-292.

Weinberger DR (1997). The biological basis of schizophrenia: new directions. J Clin Psychiatry 58(Suppl 10): 22-27.

West MJ (1993). New stereological methods for counting neurons. Neurobiol Aging 14: 275-285.

Wiley JL, Buhler KG, Lavecchia KL, Johnson KM (2003). Pharmacological challenge reveals long-term effects of postnatal phencyclidine on delayed spatial alternation in rats. Prog Neuropsychopharmacol Biol Psychiatry 27: 867-873.

Yoon WJ, Won SJ, Ryu BR, Gwag BJ (2003). Blockade of ionotropic glutamate receptors produces neuronal apoptosis through the Bax-cytochrome $c$-caspase pathway: the causative role of $\mathrm{Ca}^{2+}$ deficiency. J Neurochem 85: 525-533.

Young C, Klocke BJ, Tenkova T, Chio J, Labruyere J, Qin Y-Q et al (2003). Ethanol-induced neuronal apoptosis in vivo requires BAX in the developing mouse brain. Cell Death Differ 10: 11481155.

Young C, Roth KA, Klocke BJ, West T, Holtzman DM, Labruyere J et al (2005). Role of caspase-3 in ethanol-induced developmental neurodegeneration. Neurobiol Dis 20: 608-614.

Yuan J, Shaham S, Ledoux S, Ellis HM, Horvitz HR (1993). The $C$. elegans cell death gene ced- 3 encodes a protein similar to mammalian interleukin-1 beta-converting enzyme. Cell 19: $641-652$. 